\title{
Participación ciudadana en metodologías para el diseño arquitectónico, urbano y de paisaje
}

\author{
Laura Chaverri-Flores
}

\section{Artículo}

Afiliaciónes: Universidad de Costa Rica. Instituto Tecnológico de Costa Rica, San José. Costa Rica.

\section{E-mail: laura.chaverri@ucr.ac.cr} lauchaverri@itcr.ac.cr

Recibido: 21 de febrero del 2019 Aceptado: 7 de noviembre del 2019

\section{Laura Chaverri-Flores}

Arquitecta y máster en Paisajismo y Diseño de Sitio de la Universidad de Costa Rica. Se desempeña como profesora e investigadora de la UCR y es coordinadora de la Maestría de Paisajismo y Diseño de Sitio. Además, labora en el Tecnológico de Costa Rica y trabaja de manera independiente en proyectos de diseño arquitectónico y de arquitectura de paisaje.

\begin{abstract}
Resumen
En los últimos años se ha puesto en evidencia la importancia del diseño participativo en proyectos arquitectónicos, urbanos o paisajísticos. En este artículo se reflexionará sobre la tendencia a utilizar el diseño participativo como un requisito y no como una herramienta de diseño. En este sentido, ¿Qué tan importante es la participación ciudadana en los procesos de diseño del espacio público y privado? ¿Qué nuevos métodos y procesos se pueden reproducir dentro de este enfoque participativo para potenciar mejores prácticas en el diseño? Se examinan con atención los actores en el diseño participativo, enfatizando el rol de los profesionales, de los usuarios y otros relacionados. Posteriormente, se analizan 4 casos de estudio: el proyecto urbano y paisajístico "Place d'Armes" en Yverton, Suiza; el proyecto arquitectónico de vivienda colectiva de interés social "Conjunto habitacional Violeta Parra" en Iquique de Elemental dirigido por Alejandro Aravena; el proyecto de arquitectura de paisaje "Le Quais de Bordeaux" de Michel Corajoud y, finalmente, la propuesta de protección ambiental y desarrollo urbano paisajístico para Finca 3 de la Universidad de Costa Rica, dirigido por la autora. Para el análisis de estos 4 casos, se hace hincapié en determinar quiénes fueron los actores, las herramientas y procesos, así como los resultados de la participación. Se analizan las metodologías para culminar con un análisis sobre la importancia del diseño participativo y su incidencia en el proceso de diseño tanto arquitectónico, urbano, como de arquitectura de paisaje.
\end{abstract}

Palabras Clave: arquitectura del paisaje; diseño participativo; diseño urbano; métodos.

Citizen participation in methodologies for architectural, urban and landscape design

\begin{abstract}
:
In recent years, the importance of participatory design in architectural, urban or landscape projects has become evident. This article will reflect on the tendency to use participatory design as a requirement and not as a design tool. Therefore, how important is citizen participation in the design processes of public and private space? What new methods and processes can be reproduced within this participatory approach to promote better design practices? The actors in participatory design are examined with attention, emphasizing the role of professionals, users, and others. Subsequently, 4 study cases are analyzed: the urban and landscape project "Place d'Armes" in Yverton, Switzerland; the architectural project of collective housing of social interest Violeta Parra in Iquique of Elemental, directed by Alejandro Aravena; the landscape architecture project "Le Quais de Bordeaux" by Michel Corajoud; and finally, the proposal for environmental protection and landscape urban development for "Finca 3" of the University of Costa Rica, which I directed. When analyzing these 4 cases, the emphasis is on determining who were the actors, the tools and processes, as well as the results of the participation. The methodologies are studied in order to culminate with an analysis on the importance of participatory design, and its impact on the design process of architecture, landscape architecture, and urban design.
\end{abstract}

Keywords: landscape architecture; participatory design; urban design; methods. 


\section{Introducción}

os siglos XIX yXX dieron nacimiento al movimiento moderno, marcado por una importante renovación en cuanto a la concepción de la ciudad y de la arquitectura. Sus máximos exponentes fueron Le Corbusier, Mies Van Der Rohe, Walter Gropius, Alvar Aalto y Frank Lloyd Wright, quienes establecieron junto a sus seguidores nuevos lenguajes formales y ciudades utópicas desprovistas de referentes históricos. La famosa frase de Mies Van der Rohe "menos es más" fue el lema de una arquitectura sin ornamento que se difundió en todo el mundo, generándose proyectos muy similares formalmente sin un estudio cultural ni contextual exhaustivo. Con el movimiento moderno, se generó la utopía de la igualdad y de lo universal. Le Corbusier, por ejemplo, crea al "modulor", un personaje universal para el diseño antropométrico de sus ciudades. Sin embargo, bajo este movimiento se dejaba por fuera al usuario que no alcanzaba la medida de un hombre adulto, a la persona obesa o a la persona en silla de ruedas. De igual manera, estas premisas de diseño fueron difundidas en el mundo Occidental, trasladándose a diferentes partes del mundo como el Lejano Oriente, África y Latinoamérica, sin una preocupación específica por cada usuario y su cultura.

El nacimiento de nuevas ciudades con edificios en forma de cajas con muros cortina va a generar descontento en las poblaciones cansadas de la monotonía y de la poca preocupación por el espacio público y la particularidad contextual de cada entorno. Es así como la demolición de las casas de alquiler de Minoru Yamasaki va a representar para muchos la muerte de la arquitectura moderna, que dio nacimiento a otras tendencias arquitectónicas como la arquitectura posmoderna. Robert Venturi, Denise Scott Brown y Steven Izebour (2008) afirmaron que: "aprender del paisaje existente es la manera de ser un arquitecto revolucionario. Y no de un modo obvio, como ese arrasar París para empezar de nuevo que proponía Le Corbusier en los años veinte, sino de un modo distinto, más tolerante" (p. 22). Lyotard (1989) en su libro "La condition postmoderne: rapport sur le savoir" expone la muerte de los meta relatos y alerta a comprender las diferencias, la diversidad, la incompatibilidad de las aspiraciones, creencias y deseos. Por otro lado, alude a la importancia de la experiencia y no solo del discurso. Bajo este contexto, Jane Jacobs, activista estadounidense, en su libro "The Death and Life of Great American Cities" (1961), va a proponer una ciudad humanizada. Para Jacobs, "las ciudades van a tener la capacidad de proveer algo a todo el mundo, solo cuando esta, haya sido creada por todo el mundo" (p. 318) (N. del T.). ${ }^{1}$

En los últimos años, se ha puesto en evidencia la importancia del diseño participativo. Se ha vuelto más usual la participación ciudadana tanto en proyectos arquitectónicos, urbanos o paisajísticos, públicos y privados, así como en la vida social y política por medio de políticas públicas o plataformas. Este tema fue uno de los 6 principales tratados en el Congreso internacional de la Cumbre Mundial de Diseño. ${ }^{2}$

Las disciplinas de diseño como la arquitectura, el diseño urbano y el paisajismo contribuyen enormemente en la construcción del espacio público y social en la ciudad, así como en fomentar la cultura y modos de vida en la misma. Un mal diseño podría generar muy poco sentido de pertenencia y, por lo tanto, baja visitación y desapego, mientras que uno bueno puede potenciar el contacto social y nuevas formas de acercamiento entre los habitantes. Desde esta perspectiva, se intentará responder a las siguientes interrogantes: ¿La tendencia al uso del diseño participativo responde a una moda, imposición o es una herramienta de diseño? ¿Cómo ha cambiado la concepción

$1 \quad$ Les villes ont la capacité de fournir quelque chose pour tout le monde, seulement parce que, et seulement si, elles sont créées par tout le monde.

2 "International Congress of the World Design Summit", celebrado en octubre del 2017 en la ciudad de Montreal, bajo el lema 10 días para cambiar el mundo. del arquitecto sabelotodo que, sin consultar a nadie, formaba espacio público, privado, y ciudad? ¿Cuál es el rol y el estado del diseñador y de los usuarios en los procesos de diseño participativo a menudo consultativo y colaborativo? ¿Qué tan importante es la participación ciudadana en los procesos de diseño en la ciudad? ¿Qué aportes tuvo en el proyecto Protección ambiental en Finca 3, el insumo de la participación ciudadana? ¿Qué nuevos métodos y procesos se pueden reproducir dentro de este enfoque participativo para potenciar mejores prácticas en el diseño? 


\section{Metodología}

Para realizar esta investigación, se eligieron 4 casos de estudio con procesos de diseño participativo con el fin de analizar cuál ha sido su impacto y repercusión en las prácticas de diseño contemporáneo. El aporte de este trabajo consiste en traer a la mesa el tema del diseño participativo y descubrir diversas metodologías en su planteamiento desde diferentes abordajes teóricos de disciplinas de diseño. Para evitar repetición de conocimientos, se eligieron estudios de casos muy diferentes en cuanto a escalas, contexto y hasta disciplina.

En primer lugar, se reflexiona sobre la tendencia a utilizar el diseño participativo como un requisito y no como una herramienta de diseño. Luego, se examinan con atención los actores en el diseño participativo desde diferentes autores que han reflexionado al respecto. Posteriormente, se analizan los 4 casos de estudio haciendo hincapié en quienes fueron los actores, las herramientas y procesos, así como los resultados de la participación. Seguidamente, se analizan las metodologías para culminar con un análisis sobre la importancia del diseño participativo y su incidencia en el proceso de diseño tanto arquitectónico, urbano y de arquitectura de paisaje.

\section{¿Participación por compromiso o para el diseño?}

En Latinoamérica, se ha venido desarrollando cierta desconfianza hacia el término participativo, que muchas veces se asocia a un cumplimiento 0 acto político aislado que no culmina en nada. En este sentido, para Fabio Márquez (2011), diseñador del paisaje argentino, "la tarea de producir procesos de planificación, diseño o gestión participativa tiene un esfuerzo extra, que es revalorizar la instancia de la participación social activa de manera genuina" (p. 20). Para Márquez (2011):

Un proyecto debe tener como premisa fundamental para establecer parámetros del buen diseño, su capacidad de fortalecer los lazos sociales en el tejido barrial, estimular la solidaridad, la tolerancia, el respeto al otro diferente, la integración, sumar valores colectivos de apropiación de lo público, y esto no se expresa materialmente si no hubo un proceso en que lo material posea la carga de estos valores, que se producen por los que participaron en esa materialización, de modo concreto, colectivo y con pertenencia al objeto. (p. 24)

Además, se ha potenciado la participación pasiva, donde se informa a la población de un proyecto de diseño y se asume que hubo participación. Contrariamente, "la participación social debe ser transformadora y para ello debe ser activa, con una metodología con técnicas que permitan que todos se expresen, que circule libremente la información" (Márquez, 2011, p. 25).

Figura 1. Afiches del Congreso. Fuente: Organizadores de World Design Summit, Montreal, 2017.

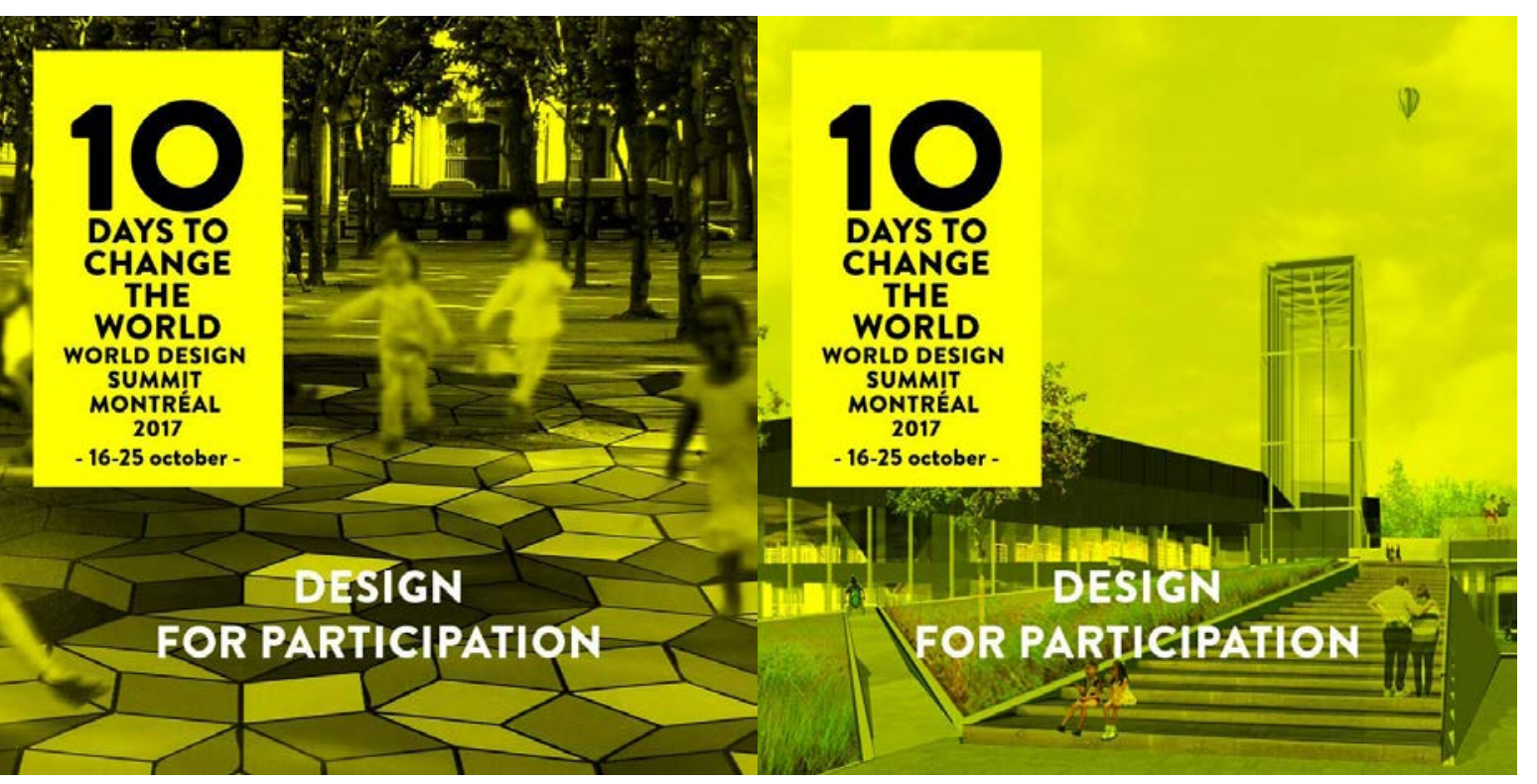


Actores del diseño participativo: usuarios

En la construcción de nuevos proyectos arquitectónicos, paisajísticos o urbanos, en algunos casos polémicos en otros muy aceptados por la población, en general se desprenden preguntas metodológicas como ¿quiénes deben ser parte de los actores del diseño participativo? ¿Cuántas personas se involucran? ¿Cómo evitar la exclusión? ¿Cómo involucrar actores que no excluyan a los grupos marginados o subalternos?

En primera instancia, el usuario directo debe ser el más consultado; por ejemplo, en el caso de una vivienda unifamiliar generalmente los arquitectos tienen largas pláticas con sus clientes. Sin embargo, muchas veces se excluyen de las discusiones a los niños, adultos mayores, algún miembro de la familia o a los vecinos que de alguna forma se relacionarán con el nuevo diseño. Lo más común en sociedades machistas es que el hombre sea quien tome las decisiones más importantes de la nueva vivienda. No obstante, a pesar de muchas conductas machistas naturalizadas, el planeamiento de la vivienda del siglo XXI ha visto nacer nuevos tipos de usuarios. Desde esta perspectiva, es importante comprender las nuevas necesidades, que en algunos casos se trata de personas que deciden no tener pareja, ni hijos y que en ciertas ocasiones comparten con una mascota, o en otros en donde se trata de parejas homosexuales o familias que incluyen abuelos y tíos, entre otros.

Como se ha indicado, desde el punto de vista del proyecto arquitectónico donde un cliente contrata a un arquitecto para generar su propio espacio, se observa cierta complejidad en la definición de los actores en el diseño participativo. Esta búsqueda se vuelve mucho más compleja cuando un desarrollador, por ejemplo, plantea edificios multifamiliares para la venta 0 en proyectos como centros comerciales o espacio público. Es obvio, como en el caso de una casa unifamiliar, que cada proyecto tendrá su particularidad y que los nuevos habitantes determinarán gran parte de las necesidades.

¿Como hacer, entonces, para incluir a todos, en sociedades latinoamericanas que históricamente han excluido a una importante parte de la población? María Lugones (2011), filósofa argentina, recuerda como en el periodo colonial "los pueblos indígenas de las Américas y los africanos esclavizados se clasificaban como no humanos en su especie-como animales, incontrolablemente sexuales y salvajes" (p. 106). Para Lugones (2011), se dio "un proceso de reducción activa de las personas y de deshumanización" (p. 108). Con la colonización, comenzó una desigualdad y racismo atroz en nuestro continente que no ha sido superado. En este sentido, muchas veces se deja de lado gran parte de la población en el diseño participativo 0, por el contrario, los diseñadores acuden a "recetas" universalistas que sirven para cualquier contexto y cualquier "tipo" de ciudadano. El problema radica en que esta universalización del espacio ha sido creada históricamente bajo premisas colonizadoras de poder que excluyen tradiciones y formas de vida fuera de la cultura Occidental, donde la generalidad se refiere al hombre blanco occidentalizado, dejando por fuera muchas veces las necesidades femeninas, etarias 0 con requisitos especiales de movilidad. Para Fischer (2003), doctora en comunicación y cultura, en la cultura occidental dominante "si se es hombre no se es mujer. Salir de la lógica binaria implica dejar de pensar linealmente, y aceptar la posibilidad de que no existan universales, ni trascendencias, ni identidades fijas, intentar no pensar dicotómicamente, es un reto cotidiano" (p. 11).

El transnacionalismo es otro fenómeno importante a incluir dentro del diseño del espacio público. Para la doctora en geografía, Ana Melisa Pardo Montaño (2015), corresponde a "una de las teorías más utilizadas en la actualidad para explicar el fenómeno migratorio" (p. 39) y se ha entendido "como una serie de movimientos entre fronteras, entre las cuales los migrantes sostienen distintas relaciones de carácter social, económico, político y cultural" (p. 48). Las migraciones pueden reconfigurar espacios sociales y los migrantes convertirse en usuarios mayoritarios por medio de la gentrificación. Un ejemplo de esto es el Parque Braulio Carrillo en Costa Rica, más conocido como el Parque de la Merced o como el Parque de los Nicas. La cantidad de usuarios nicaragüenses ha aumentado considerablemente en los últimos años, incitando el cambio de uso de algunos edificios aledaños que ahora se dedican a brindar servicios a estos usuarios, como por ejemplo los envíos de remesas. 
El diseño se vuelve complejo en espacios públicos cuando entendemos que cada individuo es particular en su necesidad. Sin embargo, se debe comprender tanto al individuo como a grupos sociales con características culturales similares. María Lugones (2011), nos recuerda la importancia de la comunidad en prácticas y tradiciones culturales y en la conformación de modos de vida:

Es importante que estos modos no son simplemente diferentes, sino que incluyen la afirmación de la vida por encima de la ganancia, el comunalismo por encima del individualismo, el "estar" por encima de la empresa, seres en relación en vez de divisiones dicotómicas una y otra vez en fragmentos organizados jerárquica y violentamente. Estos modos de ser, de valorar y de creer han persistido en la respuesta de resistencia a la colonialidad. (p.106)

Para el diseño de espacios sociales más complejos y de escalas urbanas o territoriales, es imprescindible poder conocer la cultura de los futuros usuarios, entendida como los estilos de vida, tradiciones, formas de divertirse, gustos en cuanto a comidas, olores, fiestas, entre otros.

El estilo de vida, para Bourdieu, es el resultante de una serie de prácticas de las personas. Sin embargo, en lugar de centrarse en las prácticas, Bourdieu se centra previamente en los condicionantes de tales prácticas: las condiciones de existencia están condicionando un habitus, que a su vez induce a unos esquemas generadores de prácticas y unos gustos y éstos condicionan unas prácticas que equivalen a unos estilos de vida. Los estilos de vida ayudan a configurar la clase, al mismo tiempo que son condicionados por la clase. (Álvarez, 1996, p. 153)

No obstante, para el sociólogo y filósofo francés Pierre Bourdieu, el nivel adquisitivo económico no determina la clase social ya que personas de clase popular que han ganado la lotería siguen teniendo el estilo de vida anterior. Lo que diferencia principalmente a las personas en cuanto a clase social es el gusto estético-ético (Álvarez, 1996, p. 154).

\section{Actores del diseño participativo (Profesionales)}

Según Márquez (2011), muchos profesionales se oponen a verse inmersos en estos procesos participativos ya que no los comprenden y fueron formados "bajo conceptos autoritarios y en el modelo del profesional paternalista" (p. 20). A pesar de que muchas veces se admite la necesidad que el arquitecto desarrolle destrezas psicológicas cuando se enfrenta a sus clientes en un tema tan delicado como es su espacio de vida, son pocos los cursos de psicología o sociología que llevan estos profesionales.

Para Davodeau, profesor titular de geografía en "'Institut National d'Horticulture et de Paysage (INHP) d'Angers" y Gomes Sant'anna, arquitecta del paisaje brasileña (2011) "la concepción del proyecto de paisaje está demasiado enfocado en el objeto que se va a producir y no lo suficiente en el proceso de construcción del paisaje" (p. 8) (N. del T.). ${ }^{3}$ Lamentan que su formación, en universidades francesas y brasileñas, fuera centrada en un aporte de conocimientos sobre el diseño, entendido como el saber hacer en cuanto a la disposición de los espacios y la comprensión de los paisajes y que no se integre vigorosamente la dimensión sociológica en el proceso de proyecto (p. 8). Sin embargo, aunque se coincide con estos académicos en la importancia de involucrar más fuertemente la dimensión social en la formación profesional tanto de arquitectos, paisajistas y urbanistas, también se debe potenciar a toda costa la multidisciplinaridad en todos estos procesos. Debería ser factible generar equipos de trabajo interdisciplinarios en donde sea posible involucrar profesionales relacionados con las ciencias sociales, sobre todo en proyectos de alta complejidad urbana.

\section{Caso 1. Proyecto urbano y paisajístico: "Place d'Armes" en Yverton}

Para el proyecto de reacondicionamiento o rediseño urbano y paisajístico de la plaza de Armas de la ciudad de Yverto, Suiza, se creó una metodología participativa. En la conferencia "Réflexions sur une démarche participative au pays de la démocratie directe" realizada en la Universidad de Laval en Canadá y organizada por "l'École supérieure d'aménagement du territoire et de développement régional (ÉSAD)" y el 
"Centre de recherche en aménagement et développement (CRAD)", Florent Joerin (2014) explicó el contexto que dio inicio a este proceso participativo. La plaza de $48,000 \mathrm{~m}^{2}$ a replantear estaba compuesta por 2 estacionamientos al aire libre, un parque tipo jardín japonés y un espacio con un quiosco. El nuevo diseño, por su parte, debía incorporar parqueos subterráneos y la renovación de la plaza.

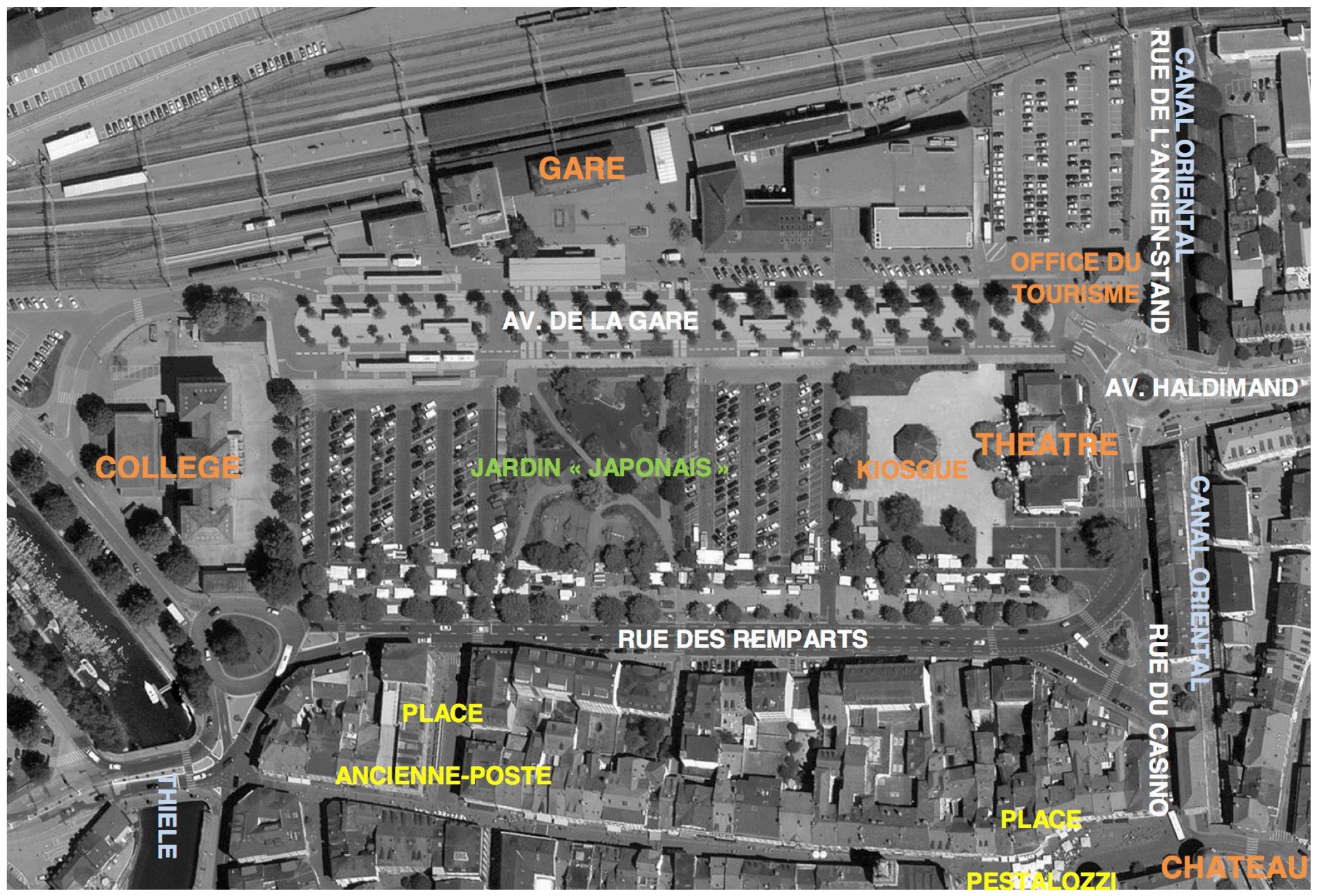

Figura 2. Foto aérea de plaza en el 2014.

Fuente: Commune d'Yverdon-les-Bains. (2014). Rapport final du Collège d'experts. Projet de réaménagement urbain et paysager de la Place d'Armes. Recuperado de http://www.yverdon-les bains.ch/fileadmin/templates/placearmes/_pdf/Rapport\%20du\%20College\%20d\%27experts_27112014.pdf

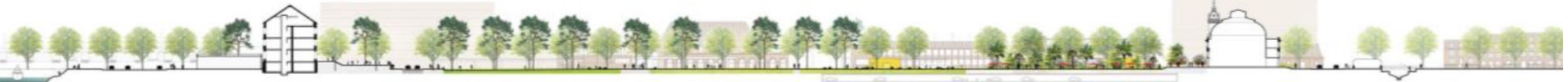

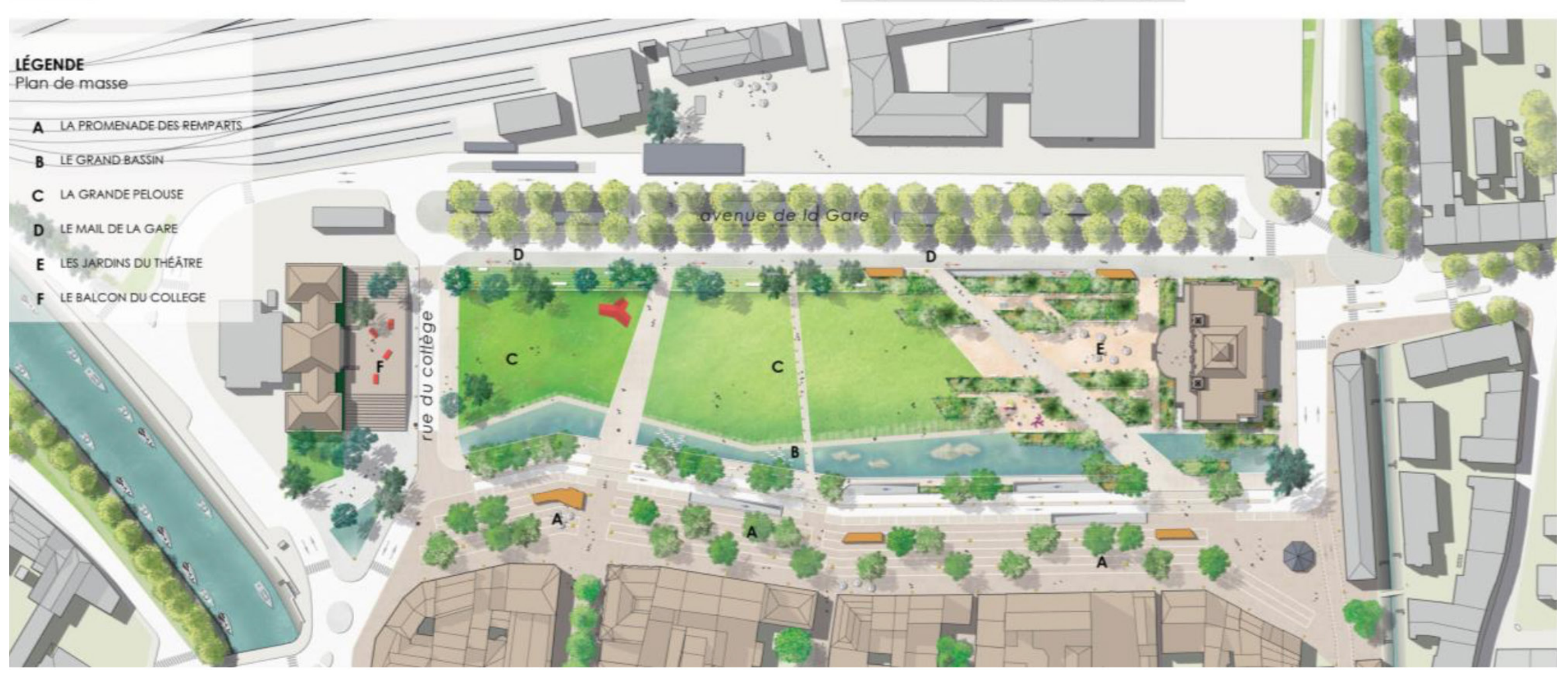

Figura 3. Propuesta ganadora.

Fuente: Commune d'Yverdon-les-Bains. (2014). Rapport final du Collège d'experts. Projet de réaménagement urbain et paysager de la Place d'Armes. Recuperado de http://www.yverdon-les bains.ch/fileadmin/templates/placearmes/_pdf/Rapport\%20du\%20College\%20d\%27experts_27112014.pdf 


\section{Objetivo del proceso participativo}

El propósito del proceso participativo fue preparar a la población para el cambio de la restructuración de la plaza, estimular la creatividad, identificar las expectativas y promover la apropiación. Se distinguieron 3 tipos de apropiaciones: la del espacio, la del proceso participativo y la del nuevo proyecto (Joerin, 2014).

El proceso participativo fue realizado con anterioridad al concurso para el rediseño de la Plaza, donde participaron 5 despachos de urbanismo y paisajismo y se eligió una propuesta ganadora, diseñada por el estudio francés de arquitectura de paisaje y urbanismo HYL P. Hannetel et A. Yver y asociados con la oficina suiza de ingeniería en mobilidad IBV Hüsler AG (Figuras 2 y 3 ).

\section{Actores}

Para contextualizar un poco los procesos participativos suizos, es importante anotar que, en la legislación de este país, existen tres niveles políticos: federal, cantonal y comunal (cada una con una escala más local). El principio de subsidiaridad indica que toda ley o decisión política se debe gestar por la autoridad política del nivel inferior, es decir, debe resolverla el nivel comunal y de no solucionarse, pasa al nivel cantonal. Existe el derecho de proposición de "Iniciativa popular" y el "referéndum popular", que se refiere al derecho de oposición (Joerin, 2014).

Hubo varios actores estratégicos. El desacuerdo marcado en el 2012 entre gobierno y población, con respecto a la construcción de una carretera de circunvalación, hizo que el gobierno local buscara generar una mejor proximidad política entre el poder político y la comunidad por medio de este proceso participativo (Joerin, 2014). El Servicio de Urbanismo y de los Edificios de la Ciudad (URBAT) de la Municipalidad contrató al Instituto G2C-HEIG-VD para el planeamiento del proceso participativo. Este instituto de Ingeniería del Territorio está compuesto por un equipo interdisciplinario de profesionales dirigido por el doctor Florent Joerin, profesor en gobernanza territorial.

Figura 4. Cadena de proceso participativo. Fuente: Joerin, (2014) https://vimeo. com/111010603

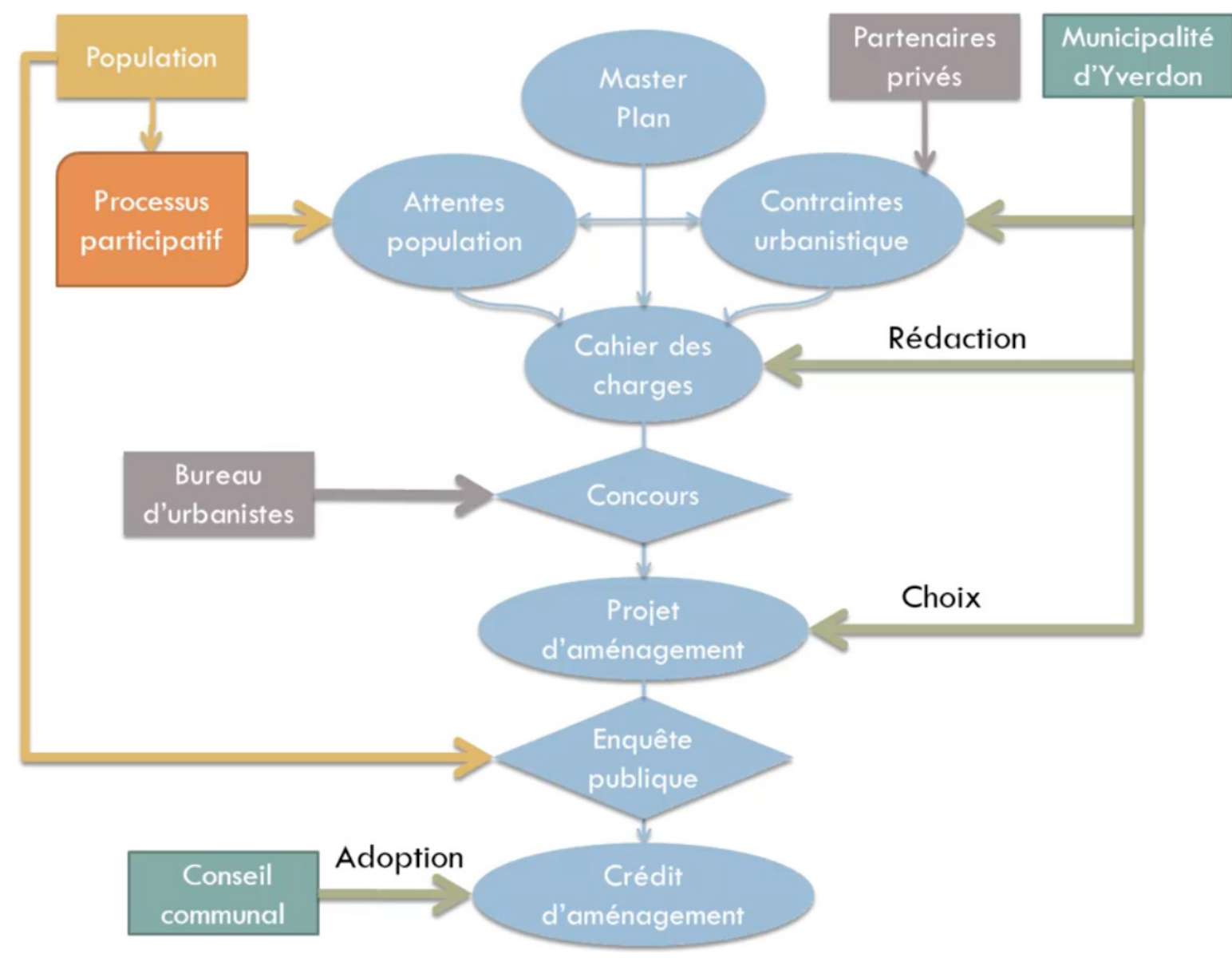




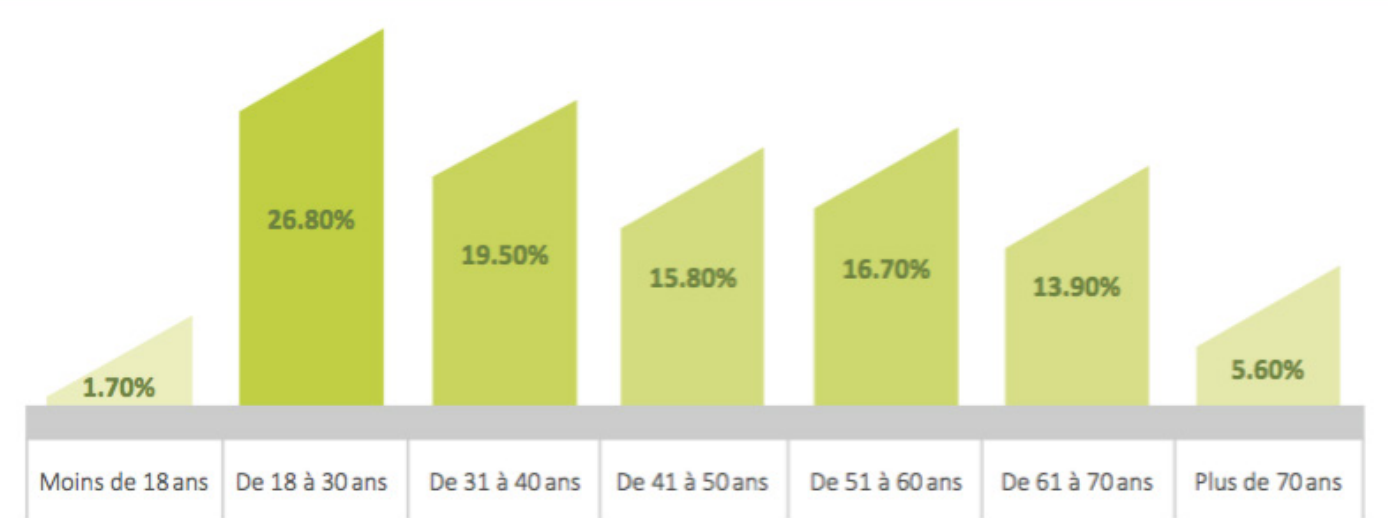

Structure de la population d'Yverdon-les-Bains par âge, en 2011

Figura 5. Estructura de encuesta por edad. Fuente: Joerin, F; Bombenger, P. H. y Cherqui, A., 2014. http://www.yverdon.ch/deppar/_pdf/ DEPPAR-RapportFinal.pdf

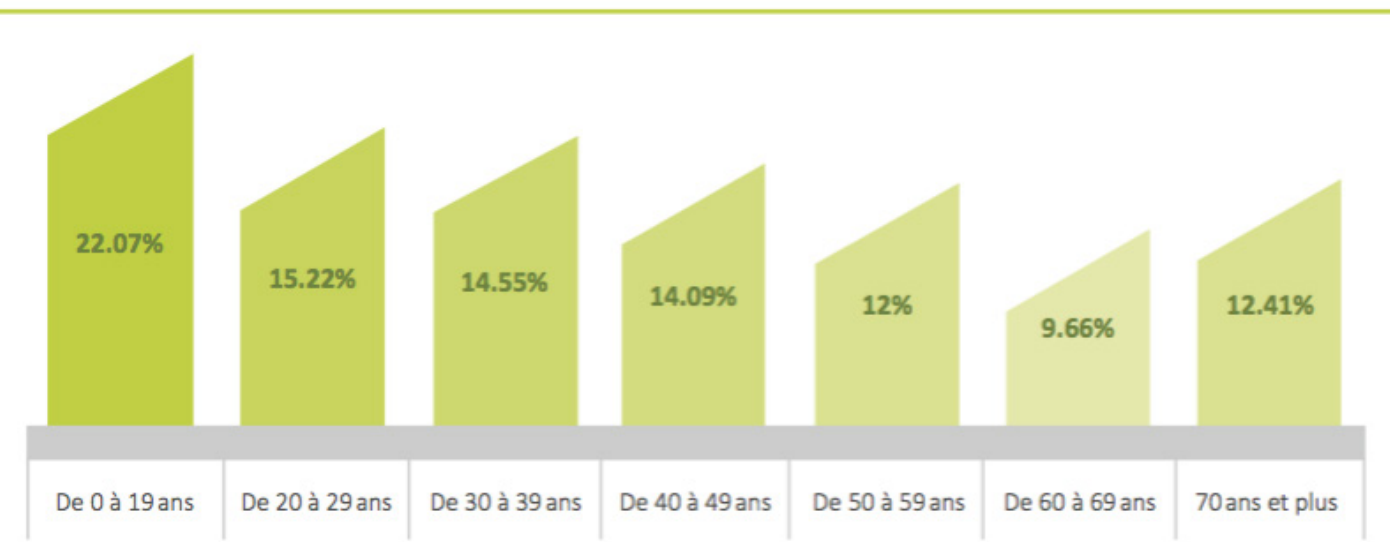

Parael proyecto final, entendido como la reestructuración dela plaza, la poblacióntuvodos momentos de participación fundamentales: en el proceso participativo y en la encuesta pública, que daría el visto bueno en la ejecución del proyecto ganador elegido por un jurado de expertos propuesto por la municipalidad (Figura 4). La población que participó en el proceso participativo fue variada. En las encuestas en línea participaron 1411 personas de las cuales $52,1 \%$ fueron hombres y 47,9 mujeres (Joerin, F., Bombenger, P. H. y Cherqui, A., 2014, p. 8) (Figura 5). Sin embargo, dentro de los documentos analizados, no quedó clara la representación de diversidades sexuales. En cuanto a la profesión, este cuestionario fue mejor acogido por personas mejor calificadas desde el punto de vista educativo, con edades de 18 a 30 años mayoritariamente. Tampoco quedó clara la cantidad de población extranjera entrevistada a pesar de que en Suiza el $23 \%$ de la población es extranjera. Es interesante que en los talleres participaron varios profesionales y estudiantes de las disciplinas de diseño, entre ellos un urbanista que presentó una charla, profesionales en áreas de diseño en la elaboración de las maquetas junto a personas de la comunidad y estudiantes de arquitectura, paisaje y urbanismo.

\section{Etapas y herramientas participativas}

Como se anota anteriormente, se llevó a cabo un largo proceso en donde el desarrollo participativo fue una de las etapas preliminares para realizar el concurso que generaría la propuesta elegida para su ejecución. El Servicio de Urbanismo de la Municipalidad redactó los lineamientos del concurso de rediseño de la plaza basados en los documentos generados del proceso participativo y las reglamentaciones urbanas. En este caso, llama la atención que los profesionales en diseño aparecieron después del proceso participativo y no formaron parte de este. Sin embargo, utilizaron toda la documentación como base para el nuevo diseño.

El proceso participativo tuvo una duración de 8 meses, ya que se pretendía progresar lentamente hacia la solución. Se puso mucho cuidado en la repartición de roles para procurar una articulación entre el conocimiento del profesional y los aportes de los habitantes. Finalmente, se promovió generar un mensaje abierto y complejo en donde las contradicciones pudieran ser un insumo para los diseñadores (Joerin, 2014). El proceso de participación se llevó a cabo en etapas con diferentes métodos que se explicarán a continuación: 


\section{La plaza de Armas, "espacios de vida de ayer y de hoy"}

Esta primera etapa tuvo por objetivo apropiarse del sitio. Como se mencionó anteriormente, la encuesta en línea fue una las herramientas aplicadas a más de 1400 habitantes. Algunas de las preguntas realizadas fueron: ¿cuáles son, según usted, las actividades típicas de una ciudad?, ¿dónde se ubican los comercios que usted frecuenta? Las encuestas utilizaron mapas interactivos para ubicar la zona de habitación de cada persona, luego se debió indicar en un mapa el lugar que cada entrevistado consideraba como el centro de la ciudad. Para formular las preguntas, se debió primero pasar por un diagnóstico del contexto. La redacción pasó por una revisión política y hubo unas preguntas que fueron negociadas entre los actores políticos y los realizadores de las encuestas. No todas las encuestas se hicieron desde la computadora, sino que existieron entrevistadores que se ubicaron en la calle con tabletas. Joerin argumentó que fue posible hacer una relación entre las respuestas y el tipo de habitante. Además, se cuestionó si la encuesta en línea siempre dice la misma cosa. Entre los encuestados se presentaron diferencias significativas, pues algunas encuestas por zonas eran muy similares, pero hubo variaciones muy fuertes entre las zonas donde se hicieron. En conclusión, aunque la tendencia arrojó respuestas similares, hubo también cierta especificidad (Joerin, 2017).

Otra herramienta fue la encuesta cualitativa con actores clave. Ésta buscaba abordar los temas de uso del espacio, la percepción y las expectativas principales. Gracias a ambas herramientas, se evidenció la utilización del sitio como un lugar de paso, de parqueo y de transición con pocos espacios que fomentan la vida pública como un pequeño mercado y juegos de niños y, a su vez, de poca interacción entre los diferentes usos. Además, la mayoría de la población entrevistada esperaba que el proyecto se tornara en un espacio verde y multifuncional (Joerin, 2014). Además, se realizó una exposición de fotografías históricas, un taller y un concurso de fotografía. Para el taller, se le proporcionaron cámaras a los participantes para que tomaran una fotografía y explicaran que significaba para ellos. Finalmente, los profesionales interpretaban que espacios eran relacionados con valoraciones positivas o negativas, por ejemplo, el Jardín Japonés fue el espacio más fotografiado y con más comentarios positivos. También se realizó un concurso de fotografía artística que contó con 31 participantes (Joerin, 2014).

\section{"Imaginar la Plaza de Armas del futuro"}

El objetivo principal era incentivar a los usuarios a soñar y proponer ideas para la intervención futura de la plaza. Se realizaron 2 talleres, el primero, el "Soirée Horizons", se realizó en la noche y se mostraron fotografías de distintas plazas en el mundo para ver cuales gustaban y discutir qué estaba bien y qué mal. Al final del evento, un urbanista explicó, de forma teórica, el significado de una plaza pública. Con esta dinámica se evidenció la particularidad de los gustos de los usuarios, por ejemplo, el agua y lo verde. De esta forma, no todas las apreciaciones que incluyeron agua 0 espacios verdes fueron apreciadas (Joerin, 2014).

El segundo taller "Urbablitz" fue un concurso de estudiantes de arquitectura, paisaje y urbanismo provenientes de Francia, Suiza, Canadá e Italia (Joerin, 2014). "Cada grupo de 3 a 5 estudiantes tuvo que concebir en un tiempo limitado (30 horas sin parar) un proyecto de desarrollo de la plaza" (Joerin, F., Bombenger, P. H. y Cherqui, A., 2014, p. 15) (N. del T.). ${ }^{4}$ Finalmente, 50 personas eligieron el premio del público y otras 50 personas les dieron seguimiento a los estudiantes. Esta actividad permitió a la población pensar la plaza diferente (Joerin, F., Bombenger, P. H. y Cherqui, A., 2014, p. 16).

$4 \quad$ Chaque groupe de 3 à 5 étudiants devait concevoir en un temps limité (30 heures non stop) un projet d'aménagement de la place.

\section{Del sueño a la realidad}

La actividad tuvo como objetivo conciliar expectativas y limitaciones. En la tercera se realizó una fase de síntesis por medio de talleres llamados "Scénarios d'aménagement". Se trabajó por medio de maquetas en tres grupos que contaban con un profesional en urbanismo y de 3 a 4 representantes de la comunidad (Joerin, 2014) (Figuras 6 y 7). 

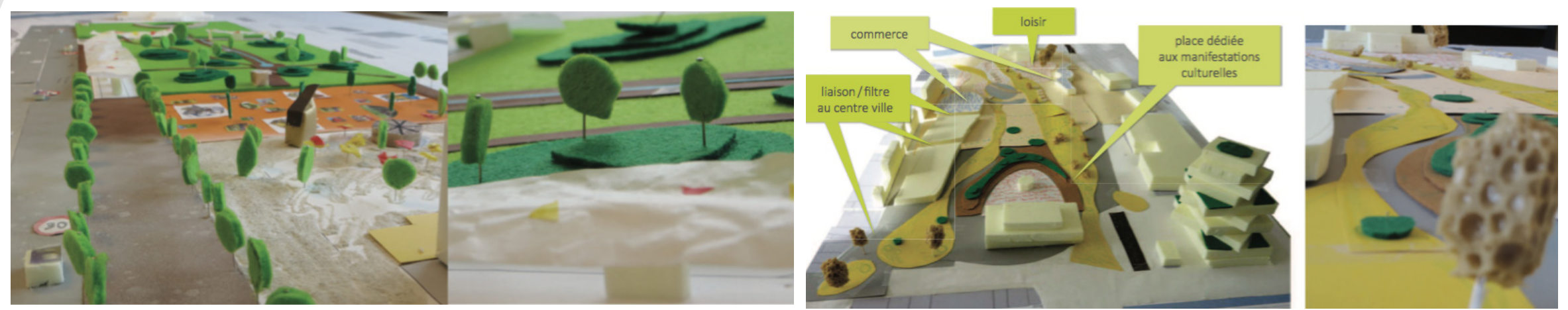

Figura 6 y 7. Maquetas realizadas por participantes en taller de rêve a la réalité.

Fuente: Joerin, F; Bombenger, P. H. y Cherqui, A., 2014. http://www.yverdon.ch/deppar/pdf/DEPPARRapportFinal.pdf
Resultados de la participación

En la última etapa, se realizó una reunión final con 80 personas, donde se mostraron las etapas y resultados (Joerin, 2014). Luego de desarrollar las 4 etapas, el Instituto G2C-HEIG-VD realizó una síntesis e interpretación de los resultados, generando las conclusiones que apoyarían el diseño y las pautas para el concurso de diseño de la plaza. Este fue sin duda un proceso participativo que tuvo mucha reflexión en su fase de planeamiento y en donde las actividades tenían una lógica secuencial. Por ejemplo, el taller "Urbablitz" ayudó a la población a pensar de una forma más utópica su propuesta, evitando los convencionalismos. Por otro lado, mientras la encuesta logró capturar "gustos" generales de la población, los talleres ayudaron a detallar particularidades en preferencias estéticas.

\section{Caso 2. Proyecto arquitectónico: Conjunto habitacional Violeta Parra en Iquique}

El arquitecto chileno Alejandro Aravena, ganador del premio Pritzker de arquitectura del 2016, y Andrés lacobelli, ingeniero industrial y máster en políticas públicas, (2016) exponen en su libro "ELEMENTAL", el proceso de diseño del proyecto de vivienda en La Quinta Monroy en la ciudad de Iquique, Chile, nombrado en su inauguración como Conjunto habitacional Violeta Parra. Se trata de un proyecto de vivienda social y colectiva para 93 familias en un terreno de $5,722 \mathrm{~m}^{2}$, construido en el 2004. El reto de diseño consistió en reutilizar el terreno que albergó a estas familias informalmente y en malas condiciones por más de 30 años y, a través del programa estatal "Chile barrio", generar proyectos de viviendas de $36 \mathrm{~m}^{2}$ cada una con opción de ampliarse al doble en el futuro. Aunque en un inicio se propuso a la población realizar el proyecto en un área fuera de lquique, ésta se opuso ya que habían realizado lazos importantes con la zona en la cual acostumbraban a vivir. De esta manera, a pesar de que se debía idear una vivienda de dimensiones reducidas por el costo del terreno, este ofrecía una apropiación por parte de los pobladores y una mejor centralidad. Aravena e lacobelli (2016) nos explican:

Cuando se entrega una vivienda es muy importante poder conservar la red social de apoyo que las familias hayan logrado crear, así como poder localizarlas cerca de la red de oportunidades que toda ciudad ofrece: cercanía al trabajo, transporte, educación, salud (...). Sólo una vivienda bien localizada en ciudad, capaz de aumentar de calidad en el tiempo y de preservar las redes sociales, puede ser una herramienta eficaz para superar la pobreza. (p. 91)

\section{Actores}

El Gobierno de Chile creó el programa "Chile Barrio" en el 2000 con el fin de comprar el terreno y formalizar la tenencia de tierras de los habitantes de este. Posteriormente, se contrató a la empresa consultora de arquitectura y diseño ELEMENTAL, liderada por Alejandro Aravena, para generar una propuesta habitacional de interés social. Los profesionales tuvieron un rol importante, pues gestionaron talleres junto con los organizadores del programa, realizaron el diseño, así como las asesorías para las ampliaciones posteriores a la entrega de las viviendas. Para Tomás Cortese, arquitecto y ejecutor del programa "Un barrio para mi familia", se efectuó una triangulación muy 
importante entre empresa privada, universidad y estado (Donoso et al., 2005). Para Silvia Araos, encargada nacional del área de infraestructura, fue posible romper las barreras sectoriales y pensar integralmente en una problemática urbana. Existió de esta forma una coordinación entre el mundo privado y público (Donoso et al., 2005).

En cuanto a los usuarios, como se explicó anteriormente, se trata de 93 familias, las cuales, antes de la propuesta de ELEMENTAL, habitaban en viviendas en muy mal estado de $30 \mathrm{~m}^{2}$; de estas un "60\% de los recintos no tenían luz o ventilación directa. No había agua potable ni conexión a la red de alcantarillado" (Aravena \& lacobelli, 2016, p. 87). Asimismo, Aravena e lacobelli (2016) explican cómo el nivel de educación era muy básico entre los habitantes, pues "un tercio de la población solo había completado la enseñanza básica (...). Las edades de los jefes de hogar eran muy heterogéneas, coexistiendo familias jóvenes encabezadas por adultos mayores" (p. 88).

\section{Etapas y herramientas participativas}

Hubo mucha desconfianza de los habitantes hacia el gobierno al inicio, ya que muchos pobladores pensaron que la propuesta era una excusa para desalojarlos y que las autoridades se quedarían con el terreno. En este sentido, se necesitó mucho diálogo para devolver la confianza a los usuarios. Por lo que, la participación ciudadana fue una condición del programa "Chile Barrio" impuesta por el gobierno a los diseñadores. Se realizaron procesos de acompañamiento a los usuarios antes y durante la construcción del nuevo proyecto, así como talleres por más de un año, una vez por semana (Aravena \& lacobelli, 2016, p. 117). A pesar de que algunos pobladores debieron ser desalojados a la fuerza, la mayoría contribuyeron en la destrucción del sitio inicial, comenzando de esta forma su participación en el nuevo proyecto.

Uno de los primeros contactos realizado por Aravena y su equipo con los pobladores fue para explicar los retos y restricciones con las cuales se contaba, ya que se trataba de un lote caro ubicado estratégicamente cerca de muchos servicios, pero de poca extensión y con restricciones presupuestarias. Algunas tipologías disponibles en el mercado como dividir el terreno en lotes con casas individuales, realizar una torre habitacional o la tipología de casa apareada en dos pisos tenían graves problemas de adecuación al lote, por lo que se descartaron. Aravena e lacobelli (2016) explican que "quedaba claro -tanto para nosotros como para las familias- que había que explorar algo inédito" (p. 98). Además, indican que "esa era la manera de evitar falsas expectativas y de dar solidez a las decisiones del proyecto" (p. 106).

La propuesta de ELEMENTAL fue la tipología del edificio en paralelo, en donde se pudieran albergar dos familias por lote y en donde cada una tuviera la opción de crecimiento por medio de la ampliación del área construida. Para Aravena e lacobelli (2016), esta fue aceptada fácilmente por los usuarios, pues "lo que estábamos proponiendo les parecía natural y casi obvio, porque de hecho ellos habían espontáneamente aplicado la misma estrategia en el campamento existente" (p. 103). No obstante, a pesar de que la tipología era conocida, no se había logrado generar una calidad de espacio apropiada, por lo que los usuarios entendían la necesidad de apoyo de los profesionales.

Los arquitectos, para adaptarse a las restricciones presupuestarias, propusieron que el $50 \%$ de la construcción sería finalizada por los propietarios de acuerdo a sus propias necesidades, gustos estéticos y particularidades. Sin embargo, establecieron normativas para que dichas ampliaciones se fueran desarrollando con armonía y respeto al conjunto edilicio. Los diseñadores dejaron de ver "la autoconstrucción como una amenaza de deterioro, para empezar a reconocerla como una manera de personalizar el espacio urbano" (Aravena \& lacobelli, 2016, p. 104). Para garantizar la calidad del conjunto y que las ampliaciones futuras fueran económicas y seguras, se idearon las estructuras coherentes a la situación final de ampliación. El ideal fue que los habitantes pudieran aspirar a una vivienda final de clase media, en cuanto a tamaños de aposentos y obra gris, por lo que los materiales que dividían las viviendas entre sí, tanto en entrepisos como muros de colindancia, fueron pensados en materiales sólidos como concreto armado. Para Aravena era fundamental construir primero lo más complejo, idear una forma que hiciera fácil las ampliaciones y erigir un edificio lo suficientemente poroso para su terminación en el futuro (Donoso et al., 2005). 


\section{Votaciones}

Una herramienta de participación utilizada fueron las votaciones, útiles para decidir sobre las condicionantes de diseño. Gracias a la votación unánime a favor de eliminar el dormitorio, el Ministerio de Vivienda otorgó el permiso de realizar esta innovación. La argumentación de esta decisión fue utilizar la experiencia profesional para realizar aposentos más complejos como cocina y baño y dejar los dormitorios para futuras ampliaciones. Por otro lado, gracias a la votación, se decidió privarse del calentador de agua, que significaba un costo importante, para en su lugar poder comprar el terreno (Aravena \& lacobelli, 2016, p. 110).

\section{Talleres participativos}

Se produjeron una serie de talleres, algunos impuestos por el programa y otros por los profesionales. En un principio, se realizó un taller con todos los usuarios donde se definieron liderazgos y se crearon 6 subcomités, conformados por los habitantes de los 4 patios y 2 frentes de manzana. De esta manera, era más sencillo hacer reuniones "por separado con grupos acotados de participantes y tratar temas específicos con mayor profundidad" (Aravena \& lacobelli, 2016, p. 123). Entre las estrategias para la mejor comprensión de los usuarios, se realizó el trazado de una casa para "conocer el tamaño y distribución a escala natural de su vivienda" (Aravena \& lacobelli, 2016, p. 123).

Se desarrollaron talleres de ampliaciones que abordaban los "crecimientos con restricciones". Se creó conciencia sobre la responsabilidad de la armonía del conjunto, en donde se mostraron facilidades y restricciones a la hora de ampliar la vivienda (Aravena \& lacobelli, 2016, p. 125). El taller enfocado en las fachadas fue de suma importancia, ya que los habitantes determinarían el $50 \%$ de la fachada en una etapa posterior, considerando el edificio como progresivo o "participativo". Los profesionales explicaron que este debía entenderse como un "ordenador de la diversidad", por lo que era necesario mantener el carácter neutral (Aravena \& lacobelli, 2016, p. 129). En este caso, se utilizó la herramienta del fotomontaje para visualizar los "resultados estéticos y prácticos de tipos de intervención" (Aravena \& lacobelli, 2016, p. 129).

Además, se desarrolló un taller enfocado en el espacio colectivo en la Universidad Arturo Prat de lquique, donde los nuevos propietarios reflexionaron sobre este y la repercusión en todos los pobladores. Los profesionales explicaron como el aumento de la plusvalía de sus viviendas no solo trascendía en el plano de la misma vivienda, pero también del barrio. Las herramientas de participación fueron el dibujo y propuestas escritas sobre lo que esperaban de los espacios colectivos (Aravena \& lacobelli, 2016, p. 133).

\section{Visitas a obra}

Tradicionalmente, las casas de interés social en Chile se entregan terminadas con nula participación en las tomas de decisiones de los usuarios. Esto contrariamente a la vivienda de clase media 0 alta en donde el cliente contrata a un arquitecto y juntos van tomando las decisiones de diseño. Bajo esta premisa y para disminuir la ansiedad por la espera, el equipo de consultores decidió llevar a los futuros propietarios a las inspecciones y así lograr la familiaridad con el proyecto, minimizando disconformidades a la hora de la entrega final (Aravena \& lacobelli, 2016, p. 125). 


\section{Asesoría de diseño}

Esta asesoría de cinco días se ejecutó luego de la entrega de las viviendas para apoyar técnicamente las ampliaciones a realizar. Aravena e lacobelli (2016) explican que "si las familias seguían el camino más fácil y barato para crecer, lo más probable es que estuvieran haciendo lo que para nosotros era 'deseable' y que coincidía con la idea de casa 'final'" (p. 175). Se trabajó el diseño de los "vacíos" a ampliar con medidas modulares de materiales conocidos para facilitar la elección de los propietarios.

\section{Encuesta}

Dieciocho meses después de la entrega de las viviendas, los consultores realizaron encuestas para determinar la satisfacción de sus "clientes", donde se enfocaron en 3 ejes: barrio, patio y vivienda. En estas "los propietarios evaluaron con un 6,5 (en escala de 1 a 7 ) el nivel de satisfacción asociado a la buena localización de la ciudad" (Aravena \& lacobelli, 2016, p. 187). Por otro lado, evaluaron con un 5.8 tanto el patio común como la vivienda.

\section{Resultados de la participación}

La participación influyó de manera importante en el diseño y en la conformación social del nuevo vecindario. Gracias a las herramientas participativas, fue posible la toma de decisiones en conjunto. Para Aravena e lacobelli (2016), el proceso en campamento transitorio, en donde se llevaron a cabo las reuniones y acuerdos para el diseño fue "el tránsito de una comunidad informal hacia una comunidad de vecinos empoderada, responsable por sus espacios comunes, capaz de interactuar sana y eficazmente en el contexto de una nueva vida de barrio" (p. 122).

Los usuarios participaron en la decisión de la conformación de los espacios externos. Los profesionales explican como en un inicio se pensó generar un gran patio central y como las viviendas se organizarían en torno al mismo. Se quería, de esta forma, romper con la relación binaria pública y privada creando espacios colectivos. No obstante, luego de varias reuniones, se comprendió que había grupos sociales específicos que buscaban espacios particulares como grupos indígenas chileno-peruanos: los aymará, grupo de "tomeros originales" y grupos de familias extensas. Fue entonces gracias a las conversaciones y necesidades expresadas por las familias que se decidió hacer 4 espacios colectivos separados de 20 familias cada uno, con acceso independiente desde la calle, contemplando la demanda de seguridad que también solicitó la comunidad (Aravena \& lacobelli, 2016, pp. 107-108).

Los resultados fueron los siguientes, "apenas dos meses después del traslado, se registró casi un $60 \%$ de ampliaciones satisfactoriamente realizadas desde el punto de vista técnico, la gran mayoría de ellas efectuadas siguiendo las recomendaciones entregadas en los talleres" (Aravena \& lacobelli, 2016, p. 126). Solo 3 casos realizaron ampliaciones con materiales inapropiados, por lo que se tuvo que demoler según el reglamento de incumplimiento, no obstante, estos usuarios no habían participado en los talleres. En cuanto a las fachadas, "un $90 \%$ de las ampliaciones realizadas dejaron balcones de acceso, tal como se propuso en los talleres" (Aravena \& lacobelli, 2016, p. 129) (Figuras 8 y 9). Menos de un 10\% de las obras se salieron de lo que los diseñadores esperaron o previnieron (Aravena \& lacobelli, 2016, p. 176).

Tal como se pretendía, cada familia pudo amoldarse a su situación particular. Por ejemplo, doña Berice de 71 años, quien vivía sola, decidió utilizar el espacio de la ampliación como un dormitorio independiente para alquilar. Por su parte, la familia de don Saddy Cruz, un mecánico de 37 años junto con su esposa y sus 3 hijos, decidieron realizar 2 cuartos adicionales y cambiaron la ducha por una tina (Aravena \& lacobelli, 2016, pp. 179-181). 


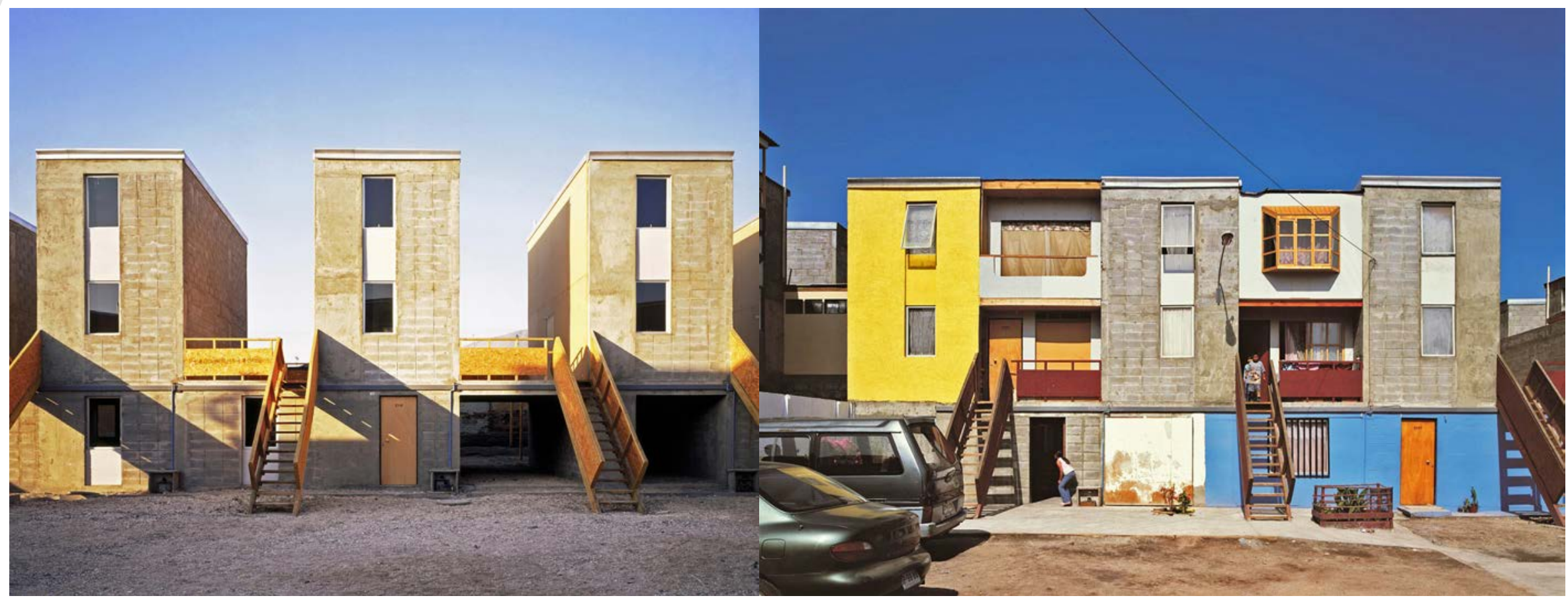

Figura 8 y 9 . Conjunto habitacional en diciembre 2004 (izquierda) y junio 2006 (derecha).

Fuente: Aravena, A. y Lacobelli, A. (2016). ELEMENTAL, Manual de vivienda incremental y diseño participativo. Alemania: Jatje Cantz.

La participación no hubiese sido tan importante si por parte de los profesionales no existiese un planeamiento previo de las ampliaciones y el diseño de espacios neutrales. De esta manera, la inversión del estado de aproximadamente 7,500 dólares, más la de los propietarios de $\$ 750$ por vivienda, generó edificaciones terminadas calculadas en el mercado en 20,000 dólares, es decir, en más del doble de la inversión. El interés fundamental del equipo de Aravena fue maximizar el uso de los recursos públicos, incorporando el diseño de la incrementalidad (Aravena \& lacobelli, 2016, pp. 190-191).

\section{Caso 3. Proyecto de arquitectura de paisaje "Le Quais Rive Gauche de Bordeaux": Michel Corajoud}

El muelle de Burdeos fue un proyecto de paisaje de 36 hectáreas, que comprendió 4.5 kilómetros de muelle por 80 metros de largo. Este se ubica en el río de la Garonne y consistió en la renovación de un muelle industrial en un parque urbano contemporáneo de espacio público. En la conferencia brindada en el 2012 durante la Jornada Departamental del Paisaje, organizada por el Consejo General de Haute Savoi, Michel Corajoud reflexionó sobre el diseño del paisaje de este muelle. Para Corajoud (2012), ya la belleza estaba presente en el sitio representada por el río con tierra, emulando vino y hermosas agujas de las iglesias. Corajoud decidió en lugar de imponerse al paisaje aprovechar las bondades estéticas existentes y valorizarlas (Figuras 10 y 11).

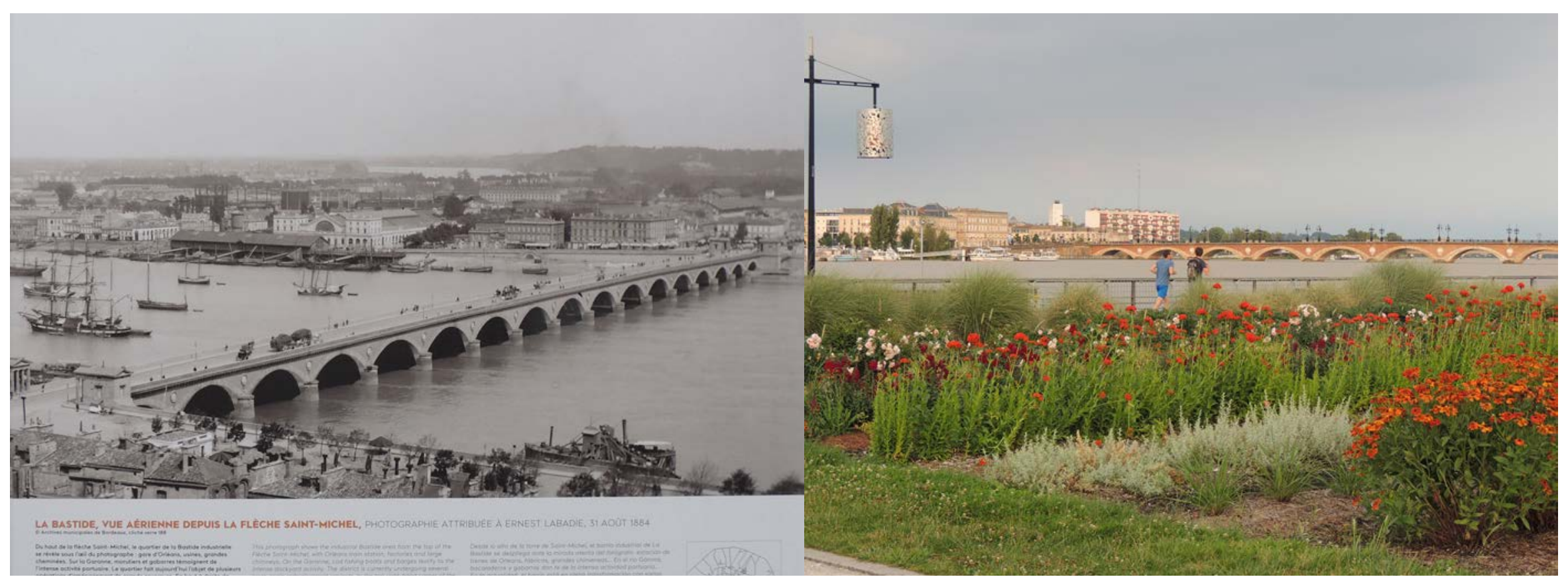

Figura 10. (Izquierda) Fotografía histórica mostrando importante actividad portuaria Figura 11. (Derecha) Fotografía mostrando jardines lineales. Fuente: Elaboración propia, 16 de junio 2015.
La Ciudad de Burdeos ha sido declarada patrimonio de la humanidad por su gran legado de arquitectura histórica. Esta propuesta logró conectar la ciudad patrimonial con el río a través de una serie de espacios públicos, destacándose un gran espejo de agua de tan solo $3 \mathrm{~cm}$ de profundidad frente a la plaza de la Bolsa (Figuras $12 \mathrm{y}$ 13). Corajoud junto con Jean Max Llorca diseñaron dicho espejo para poner en valor 
la belleza de las fachadas de los edificios del siglo XVIII que se reflejan en el agua. Además, el agua contribuye a mejorar el confort térmico en los calurosos meses de verano y funciona como un atractor en las actividades de este gran espacio público. Gracias a la poca profundidad, las personas se quitan los zapatos y recorren esta fuente al ritmo de los efectos de la misma, donde por momentos el agua sale en chorros y en otros como niebla. El concepto fue volver a poner la Garonne en el lugar, ya que gracias al espejo se siente una continuidad entre el río y el muelle (Corajoud, 2012). Junto con la propuesta paisajística también se construyó el tranvía en el 2007, potenciando la movilidad pública.

\section{Actores}

Los actores principales de estos procesos de diseño y construcción fueron: los diseñadores, en este caso Michel Corajoud y su equipo; las autoridades locales (la municipalidad de Burdeos); inversionistas privados; técnicos de la ciudad y la "Communauté urbaine de Bordeaux" (CUB). Estos últimos se encargarían del eje técnico y económico, así como del político junto con la municipalidad (Roche, 2010-2011, p. 2). La "Communauté urbaine de Bordeaux" fue la encargada de realizar la gestión del proyecto y organizó un concurso en 1999, donde de las 5 propuestas presentadas, la de Corajoud fue la ganadora. La "mairie de Bordeaux" se asoció con la CUB para los trabajos de construcción y asumir los costos del proyecto. Además, el ayuntamiento se encargaría del mantenimiento de la obra una vez terminados los trabajos (CUB \& Marie de Bordeaux, 2009, p. 3).

El despacho de Corajoud es multidisciplinario. En este proyecto trabajó junto con otros dos paisajistas, así como con diseñadores, arquitectos, un diseñador de iluminación, un fabricante de fuentes, un investigador y un economista (Godier \& Mazel, s.f., p. 9). Para Corajoud (2012), un proyecto puede comenzar antes de que el diseñador comience a realizarlo, ya que la gente generalmente sueña con el nuevo espacio. En la conferencia brindada en el 2012, relacionó el diseño del paisaje con el inicio de una conversación con los usuarios del lugar. Desde este punto de vista, es impensable poder desarrollar un plan sin tener un diálogo abierto con los protagonistas del sitio. Además, comentó que en el momento que se liberaron los muelles de sus actividades industriales y sin ninguna intervención paisajista, los ciudadanos comenzaron a apropiarse incorporando pequeñas ferias. Desde este punto de vista, los habitantes fueron actores importantes en la concepción del proyecto.

Para Corajoud (2012), era muy importante poner en valor la tradición rural que tiene la ciudad y reconciliarla con lo urbano. Recordaba como los abuelos urbanos o los campesinos plantaban las zanahorias y hortalizas en línea. Por lo tanto, esto generó jardines lineales para evitar un jardín estático con una paleta vegetal determinada y promover que los jardineros pudieran volverse actores. Cada año las plantas se pueden cambiar totalmente e involucrar al público en general, que puede proponer especies vegetales al jardinero. En este sentido, el jardinero es otro de los actores más importantes de este proyecto pues se vuelve co-creador (Figura 14).

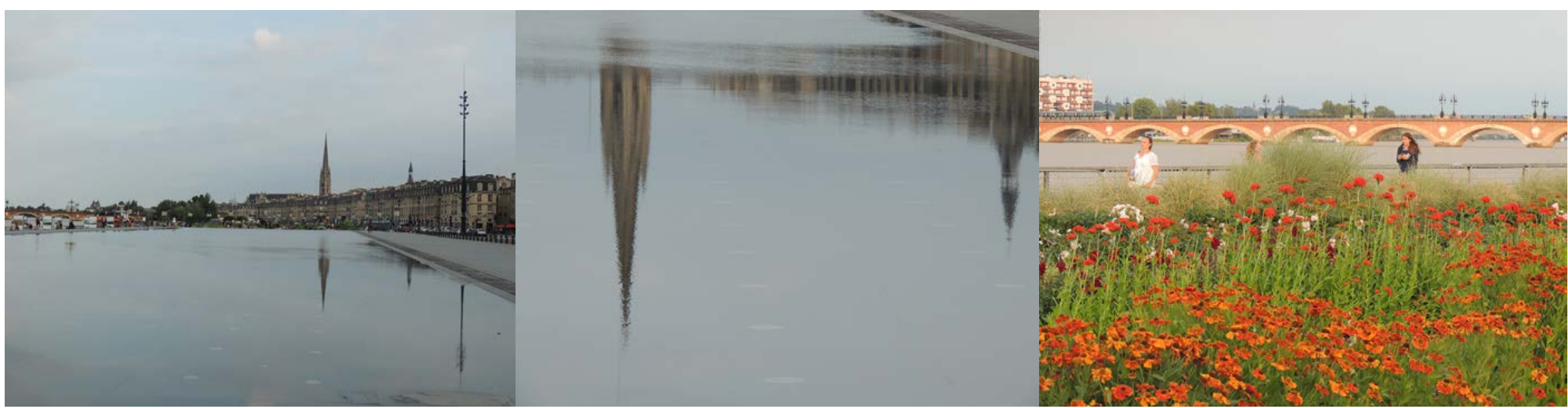

Figura 12, 13 y 14. Fotografías mostrando espejo de agua y puesta en valor de edificios A patrimoniales y río la Garonne.

Fuente: Elaboración propia, 16 de junio 2015. 
Etapas y herramientas participativas

El proceso para la concreción de este proyecto fue lento, pero atinado. Entre los años 1988 a 1994, se llevó a cabo una fase de reflexión y convocatorias como el concurso de ideas "d'Arc en Rêve". A partir de 1996, se realizaron las primeras demoliciones del puerto, que llevaron a la población a imaginarse el nuevo proyecto urbano. Entre 1998 y 1999, se realizó el planeamiento y ejecución del concurso de diseño. Para Corajoud fue muy importante la calidad del programa y los requisitos de este. Explica como la escenografía ya estaba definida y ellos debieron agregar la escritura (CUB y Marie de Bordeaux, 2009, p. 7).

Como se explicó anteriormente, los usuarios comenzaron a apropiarse del sitio con ferias antes de la propuesta de paisaje, convirtiéndo el área en un campo de experimentación. En 1998, se realizó el primer festival del vino, así como eventos para la Copa Mundial, con pantallas gigantes y cafés. Por lo tanto, se podría considerar esta etapa de participación espontánea como imprescindible en la etapa de diseño. De acuerdo con el archivo de prensa presentado por la municipalidad y la CUB (2009), nunca hubo oposición de la población hacia el proyecto (p. 6). Esto parece ser lógico pues se logró determinar atinadamente las necesidades.

La etapa de construcción tuvo una duración de 9 años (2000-2009). En el 2000, se presentó la propuesta ganadora de Corajoud al consejo municipal y al consejo de barrio. Ese último consiste en reuniones públicas abiertas a todos los habitantes, donde se debaten y comparten ideas y proyectos para el mismo. En el proceso de construcción se realizaron reuniones regulares con los habitantes de Chartrons. Para Corajoud, uno de los aspectos más exitosos y satisfactorios del proyecto fue la adhesión espontánea e intensa de los habitantes. Al inicio, algunos vecinos se preocuparon por los nuevos árboles plantados que obstruirían su vista hacia la Garona, pero rápidamente comprendieron que el papel de filtro de los árboles daba transparencia en invierno y sombra en verano. Estas mismas personas vinieron luego a solicitar la lista de especies para conocer los períodos de floración (CUB y Marie de Bordeaux, 2009, p. 7). Thierry Guichard, jefe de proyecto de la CUB, explicó también como las personas se apropiaban de los sitios desde el periodo de construcción, traspasando las barreras y accediendo al sitio antes de su finalización, lo cual demostraba que la idea del proyecto estaba muy bien planteada (CUB y Marie de Bordeaux, 2009, p. 8).

Este proyecto se inscribe en otro mucho más grande y ambicioso, el "projet du Grand Bordeaux de 2030", que promueve una metrópolis sostenible, donde los habitantes puedan reunirse alrededor de un proyecto colectivo esencial para reforzar la "cultura viva" (Marie de Bordeaux, 2011, p. 10).

\section{Resultados del proceso de participación}

Para CUB y Marie de Bordeaux (2009), en un tiempo récord, este espacio se ha convertido en un verdadero lugar de vida, pero también de reuniones de ocio y de fiesta (p. 3) (N. del T.). ${ }^{5}$ Según se explica en el archivo de prensa, el proyecto fue fácilmente aceptado y utilizado por la población, generando no solo un nuevo espacio público sino un cambio en la vida cotidiana de los habitantes. Gracias a la elaboración de una encuesta cualitativa y explorativa, Guy Tapie (2007) concluyó que la apreciación de la mayoría de los usuarios es muy positiva. Los encuestados expresaron sensaciones de libertad, apertura, tranquilidad y calidad de vida, relacionando el espacio con aire y respiro que calma la vida.

Uno de los puntos clave de la aceptación y el impacto positivo de este proyecto fue la diversidad y la accesibilidad. Este enorme espacio público abierto, se contrapuso al antiguo e inaccesible puerto industrial, donde abundaban los parqueos y bodegas. Se disminuyó la presencia de vehículos promoviendo la diversidad de diferentes medios de transporte. Este espacio se convirtió, así, en un sitio para todos, donde cada quién puede realizar actividades variadas para usuarios de diversas culturas, edades, clases sociales y gustos. De esta forma, se crearon espacios para caminar, para correr y para andar en bicicleta con múltiples jardines, así como espacios deportivos, lúdicos 
y comerciales. El "vacío" fue otro punto clave importante pues, de alguna forma, no imposibilitaba la vista hacia las fachadas y el río y potenciaba usos diversos y actividades sociales.

La diversidad de horario de uso y de mobiliario urbano fue otro aspecto importante para potenciar la apropiación. Se trabajó cuidadosamente la iluminación para evitar el uso exclusivo en horas del día. Por ejemplo, a una altura de 4.5 metros se colocaron lámparas con 2 linternas a lo largo de las sendas e iluminación en las fachadas patrimoniales. En cuanto al mobiliario urbano, se incorporaron parqueos para bicicletas, barandas para observar el río de forma segura, parrillas de protección de árboles, bancos y basureros, así como bolardos y postes bajos que impiden el acceso a los vehículos en los espacios peatonales. Además, se incluyó un muro de piedra entre el boulevard y el río con variaciones de altura y diferentes explanadas de zacate que conforman espacios para actividades individuales y colectivas, como acostarse 0 sentarse.

Lo esencial en el diseño fue pensar en el confort y el placer de la gente. Corajoud estudió la relación que tienen las personas entre la sombra y la luz, así como la proyección de los árboles para generar un espacio para vivir donde se potenciarán todos los sentidos, gracias a elementos como el agua, la vegetación y la belleza del río. Como ya se explicó anteriormente, se tomó como base la belleza existente del paisaje para ponerla en valor y evidenciarla. La discreción y la coherencia se han visto favorecidas por los elementos ya presentes en la ciudad: madera, hierro fundido y metal, del característico "bleu de Bordeaux" (Roche, 2010-2011, p.4).

La ciudad pasó de ser una en donde el automóvil era el protagonista a una con gran calidad humana, con una fácil accesibilidad al transporte público mediante el tranvía. Para Godier y Mazel (s.f.), se trata de una ruptura cultural y un cambio metodológico en concebir los espacios, ya que la nueva función social se encuentra, en este caso, orientada al bienestar y a la mejora del tiempo libre y las actividades culturales de los usuarios (p. 10). El proyecto se torna un trabajo de mediación cultural, en donde la preocupación más grande de Corajoud fue que el muelle pudiera darle felicidad a sus usuarios (Godier \& Mazel, s.f., p. 9).

\section{Caso 4. Propuesta de protección ambiental y desarrollo urbano pai- sajístico para Finca 3, Universidad de Costa Rica}

Este trabajo fue una consultoría realizada a la Universidad de Costa Rica y dirigida por la autora en el primer semestre del 2017. El resultado fue un documento que contiene los antecedentes y diagnóstico de la Finca 3 desde los ejes social, perceptual, movilidad, espacialidad, paisaje y sistemas naturales. Además, contiene el análisis del emplazamiento previsto para los nuevos proyectos constructivos, una propuesta sobre criterios integrales y recomendaciones para guiar la planeación paisajística y el desarrollo futuro de la Finca 3, con un plan paisajístico preliminar. La Finca 3, o Instalaciones Deportivas, forma parte de los terrenos que conforman la Sede Central de la UCR, ubicada en el cantón de Montes de Oca de la provincia de San José. Con un área de $234200 \mathrm{~m}^{2}$; ha sido tradicionalmente una finca relacionada con el deporte y la salud. Posee un estadio ecológico, canchas de fútbol, piscinas, senderos para trotar, así como gimnasios, la escuela de Educación Física, áreas verdes y áreas de protección asociadas al río Torres.

Tanto las cuatro fincas como los terrenos aislados de la Sede Central representan un importante pulmón urbano con remanentes vegetales del bosque húmedo premontano. A pesar de que desde su planeamiento los edificios de la UCR conformaron un "eco campus" en donde los inmuebles se integraban al entorno natural, en las últimas décadas el crecimiento ha sido desordenado y no se ha definido un plan de ordenamiento integral. Reconociendo la importancia ecológica que tienen las fincas, en abril del 2015 se acuerda declarar el $60 \%$ de la Finca 4, ubicada al oeste de la Finca 3, como una reserva de la UCR. De esta forma, algunos de los proyectos edilicios planteados por la necesidad de crecimiento de la planta física se trasladaron a la Finca 3, como por ejemplo el edificio de Odontología, generando en algunos casos pérdida de espacios verdes de esparcimiento muy valorizados por la población. En febrero del 2017, se 
Figura 15 y 16. Miembros del equipo de trabajo. Fuente: Chaverri (2017) aprueba la propuesta para elaborar un plan de Ordenamiento de la Planta Física y Territorio de la UCR y que se inicia con esta consultoría.

\section{Actores}

Para este trabajo, se definen claramente 4 tipos de actores: la Universidad, representada por la Rectoría quienes solicitaron la consultoría; el equipo profesional que contó con la asesoría de arquitectos, paisajistas, biólogos y diseñadores gráficos (Figuras 15 y 16); la comunidad universitaria que incluye estudiantes, profesores y funcionarios; y la comunidad de vecinos, usuarios frecuentes y asociaciones relacionadas con el tema de planificación de la Finca 3.

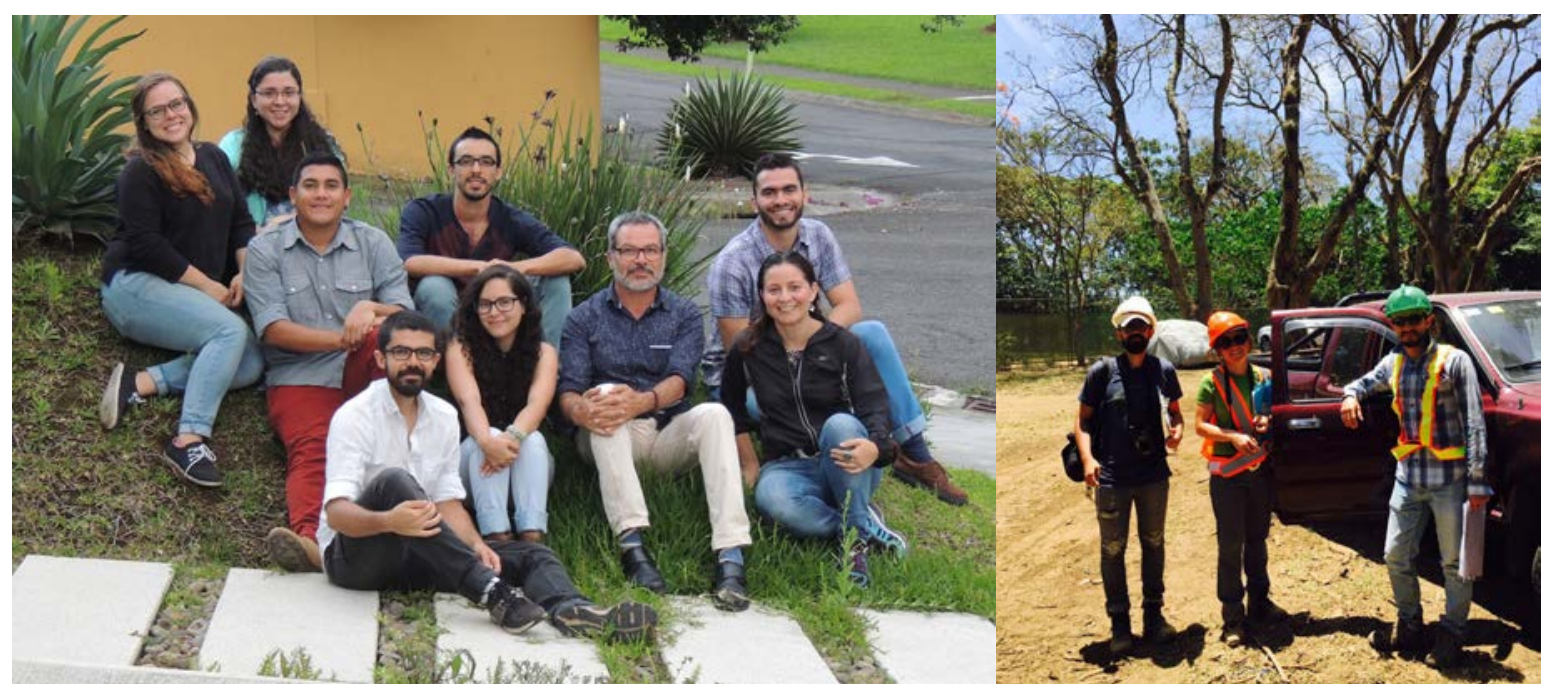

La Universidad de Costa Rica posee más de 35,000 estudiantes, 10,000 funcionarios y 170 unidades, tanto en la sede central como en las regionales a lo largo del país. En la sede central se encuentran la mayoría de los actores involucrados con la gestión ambiental y la planificación, como por ejemplo la Oficina Ejecutora del Programa de Inversiones (OEPI) inscrita a la Rectoría, la Comisión Institucional de Foresta Universitaria (CFU) inscrita a la Vicerrectoría de Administración o la Red de Áreas Protegidas (RAP) adscrita a la Vicerrectoría de Investigación.

\section{Etapas y herramientas participativas}

Para este trabajo, se realizó un diagnóstico social perceptual por medio de un proceso participativo con el fin de reconocer la zona desde diferentes actores y obtener un marco de referencia más general que contribuyera a la toma de decisiones. De esta manera, se buscó elaborar una propuesta coherente que contemplara las visiones y necesidades de los diversos grupos involucrados, definiendo la situación del sitio actual desde la percepción poblacional. Se utilizaron diferentes herramientas de participación de acuerdo con los objetivos y los temas de interés abordados. En la línea del tiempo (Figura 17), se observan las diferentes etapas y herramientas utilizadas.

\section{Cuestionarios}

Como parte de las herramientas cuantitativas y cualitativas, se realizaron 105 cuestionarios, tanto en sitio como en los talleres. Éstos permitieron indagar sobre las dinámicas y la relación de los usuarios con la zona de estudio. De esta forma, se evaluó la calidad actual del espacio de Finca 3 desde la perspectiva ciudadana, generando gran cantidad de información dividida en cuatro ejes: usuario y sitio, actividades realizadas, paisaje y condiciones físicas del sitio. En la figura 18 se pueden observar las personas entrevistadas divididas en los cuatro grupos más importantes de usuarios: estudiantes, funcionarios, visitantes y vecinos. 
Figura 17. Línea del tiempo Proceso Participativo.
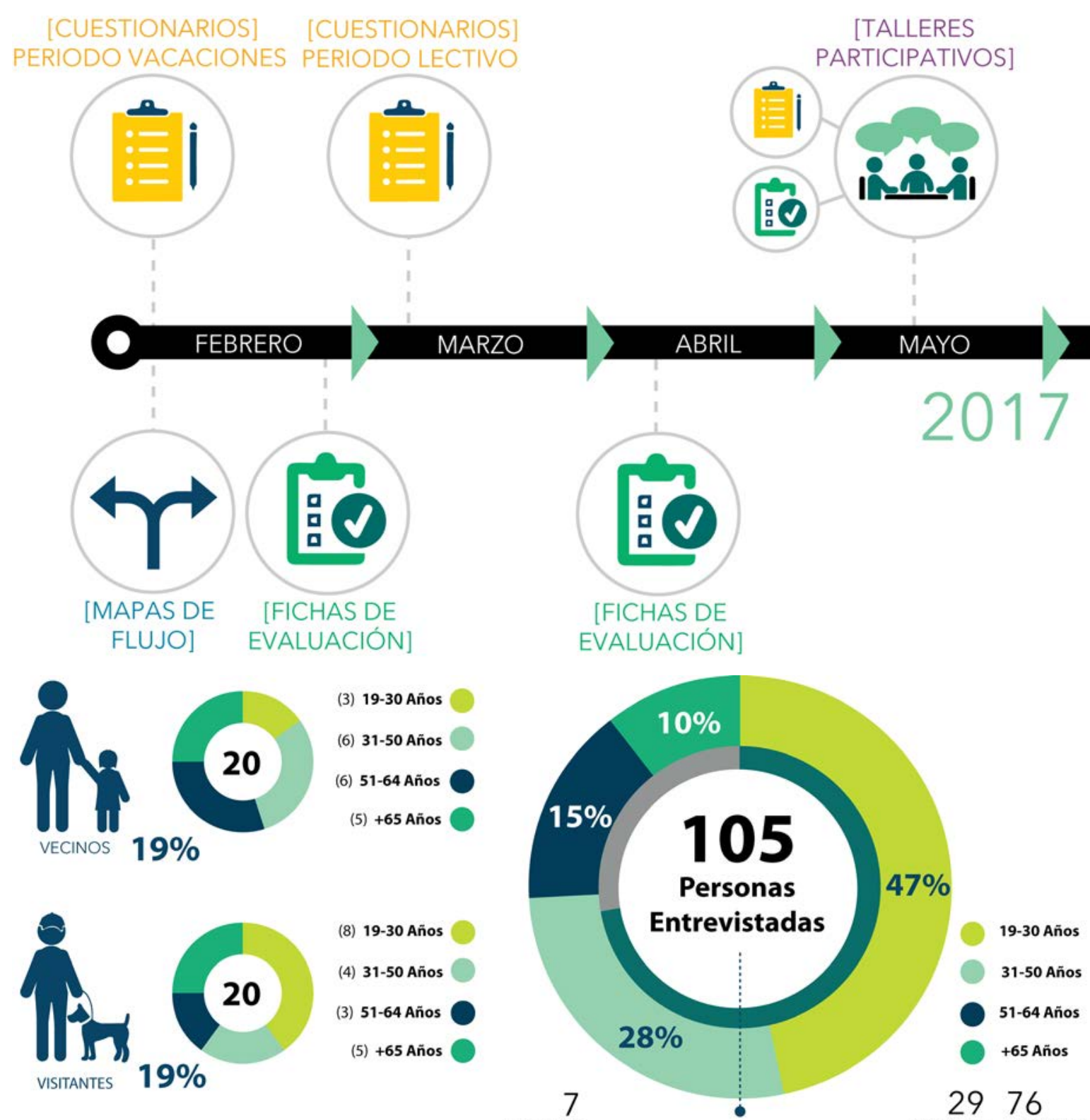

19-30 Años

31-50 Años

51-64 Años

+65 Años

2976
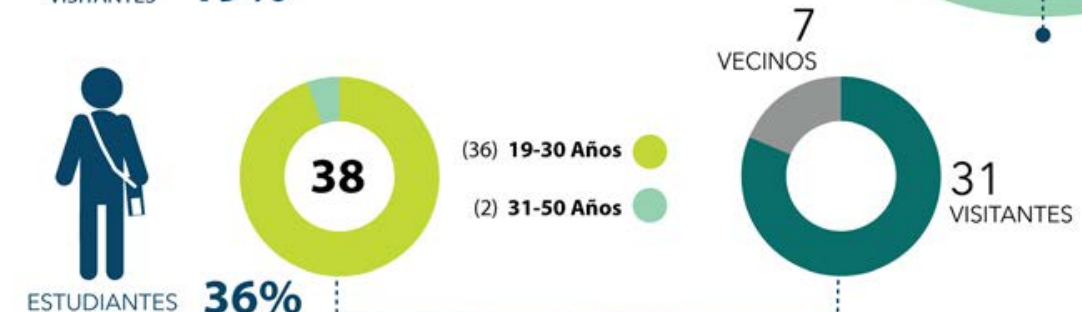

VECINOS VISITANTES

18. Grupos entrevistados. Fuente: Chaverri Flores, L. et al. (2017). Propuesta de protección ambiental y desarrollo urbano paisajístico para Finca 3 Universidad de Costa Rica. San José, Costa Rica: Universidad de Costa Rica.

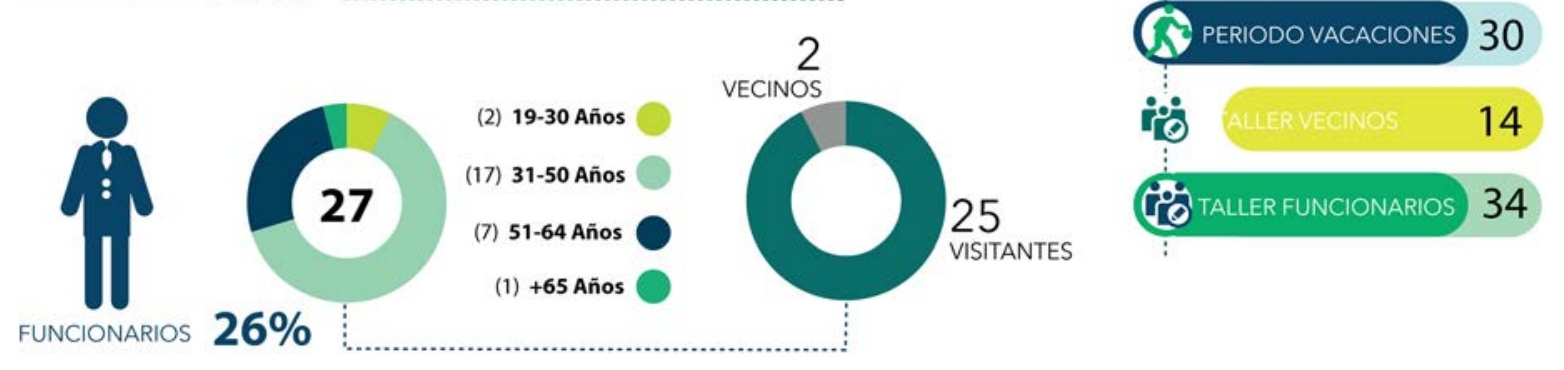

Preguntas Conductoras:

Las preguntas conductoras fueron: “Quién utiliza más el espacio?, ¿Qué piensan los usuarios de las condiciones actuales del sitio?" (Chaverri et al., 2017, p. 48).

\section{Resultado Esperado:}

"Caracterizar los diferentes tipos de usuarios que se encuentran en constante contacto con el sitio además de definir características físicas desfavorables a atacar o beneficiosas a potenciar dentro de la nueva propuesta de planificación" (Chaverri et al., 2017, p. 48).

\section{Mapas de flujo}

Los mapas de flujo fueron una herramienta cualitativa y cuantitativa utilizada. Gracias a estos fue posible detectar los recorridos peatonales más frecuentados y los sitios mejor valorizados por los usuarios. Cada persona trazó, con ayuda de un mapa brindado por el equipo profesional, tanto su recorrido habitual como sus lugares predilectos del sitio. Se realizaron 32 mapas individuales que finalmente se sobrepusieron para evidenciar las rutas más utilizadas y sitios preferidos (Figura 19). 
Preguntas Conductoras:

“Cuáles son las dinámicas del sitio relacionadas a la movilidad de los usuarios?" (Chaverri et al., 2017, p. 48).

\section{Resultado Esperado:}

"Definir las zonas de más tránsito (principales corredores peatonales) para la mitigación con respecto a aquellas obras que interfieran con dichos flujos y para su potenciación dentro de la nueva planificación" (Chaverri et al., 2017, p. 48).

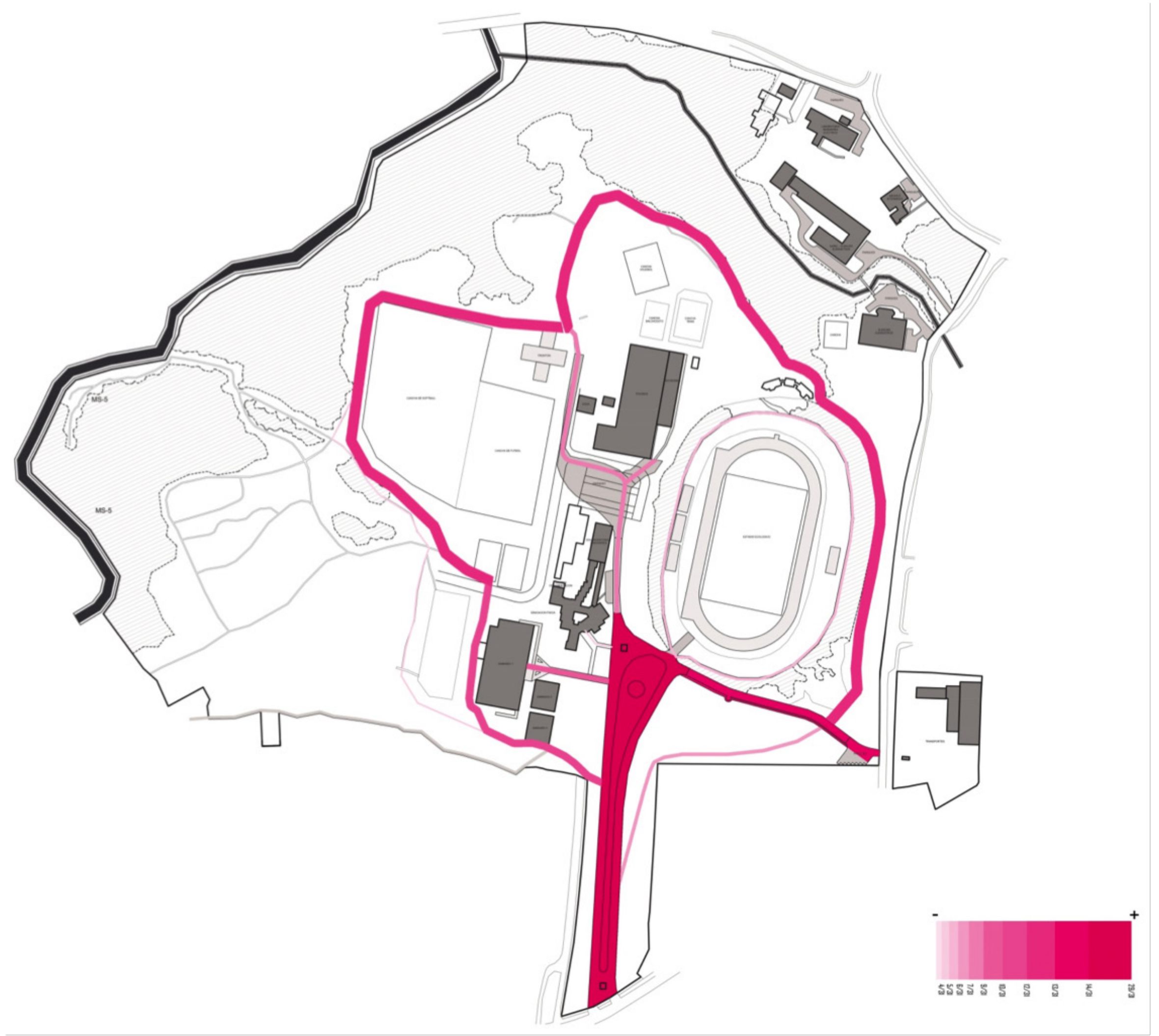

Figura 19. (Izquierda) Mapa de síntesis de flujos A peatonales. 


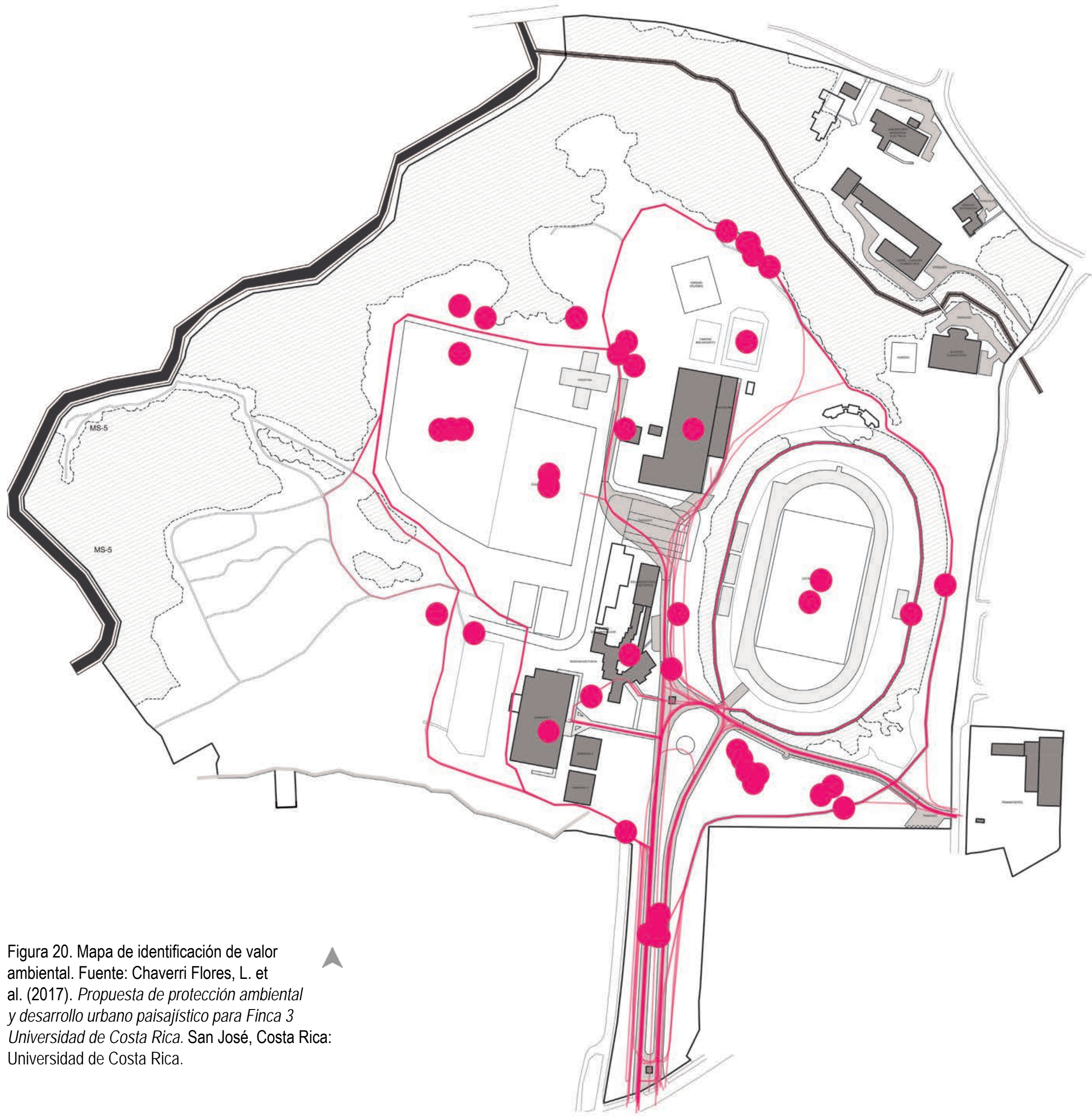

Fichas de evaluación

Se utilizaron las fichas de evaluación como herramienta de investigación cualitativa del proceso de consulta. Se proporcionaron a los usuarios fichas con imágenes de proyectos terminados de espacios, actividades y elementos paisajísticos para conocer la preferencia estética y de actividades que se podrían realizar a futuro en la Finca 3. Se mostraron diferentes imágenes donde los participantes debían escoger una carita según 3 categorías: me encanta, me gusta o no me interesa en alusión a 4 temáticas: espacios y superficies, vegetación, mobiliario y actividades programáticas coherentes con las necesidades 0 aspiraciones de las instalaciones.

\section{Preguntas Conductoras:}

"¿Qué elementos, espacios 0 actividades relacionan los usuarios con la identidad de Finca 3?" (Chaverri et al., 2017, p. 48). 


\section{Resultado Esperado:}

"Definir los espacios y actividades que se encuentran ausentes dentro del programa actual y que a consideración del usuario se vuelve necesario integrar en una nueva propuesta" (Chaverri et al., 2017, p. 48).

\section{Talleres participativos}

Se realizaron dos talleres participativos cuyos objetivos pretendían identificar las dinámicas realizadas porlos participantes, generarposiblespropuestas detransformación de la Finca 3 y comparar y discutir las propuestas. Como parte de la metodología del taller, al inicio, el equipo profesional realizó una pequeña charla (Figuras 21 y 22). Posteriormente, se realizaron grupos según la afinidad de los participantes para que, con ayuda de un mapa y una guía de trabajo proporcionados por los profesionales, se pudieran ubicar los espacios recreativos, de encuentro, concurridos, en deterioro, entre otros (Figura 24). Como resultado, cada grupo generó propuestas de mejora en los ámbitos de movilidad, ecología y ambiente, paisaje, edificaciones y servicios complementarios. En una tercera etapa, cada grupo expuso sus propuesta y reflexiones generándose un debate de ideas (Figuras 23, 25 y 26). Finalmente, la información de los mapas individuales fue simplificada en mapas de síntesis realizados por el equipo consultor (Figura 33).

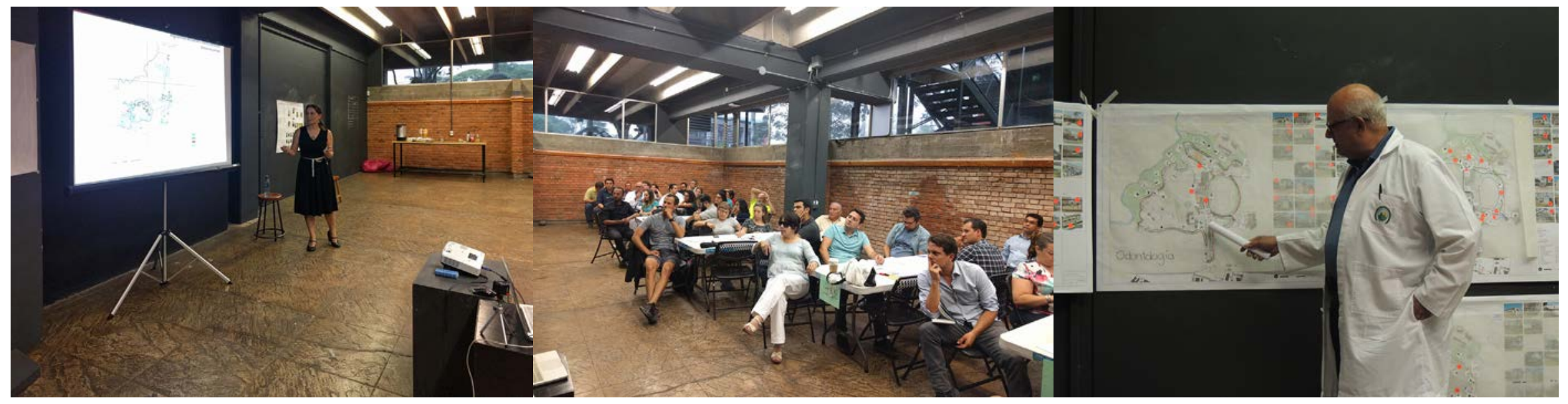

Figura 21. Charla de introducción. Fuente: Solano Monge, L. (2017).
Figura 22. Charla de introducción. Fuente: Solano Monge, L. (2017).
Figura 23. Exposición de propuesta Odontología. Fuente: Chaves Hernández, G. (2017).

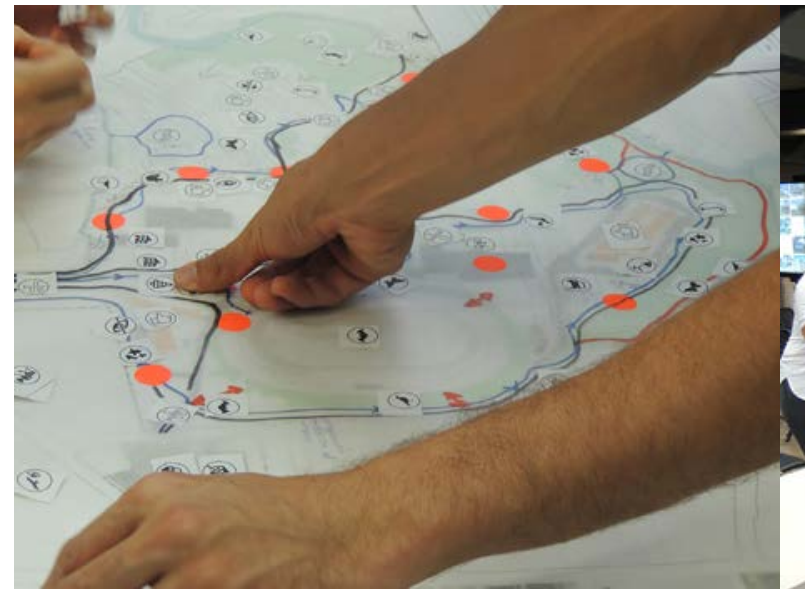

Figura 24. Procesos de trabajo. Exposición de trabajo realizado en el taller (centro). Fuente: Solano Monge, L (2017).

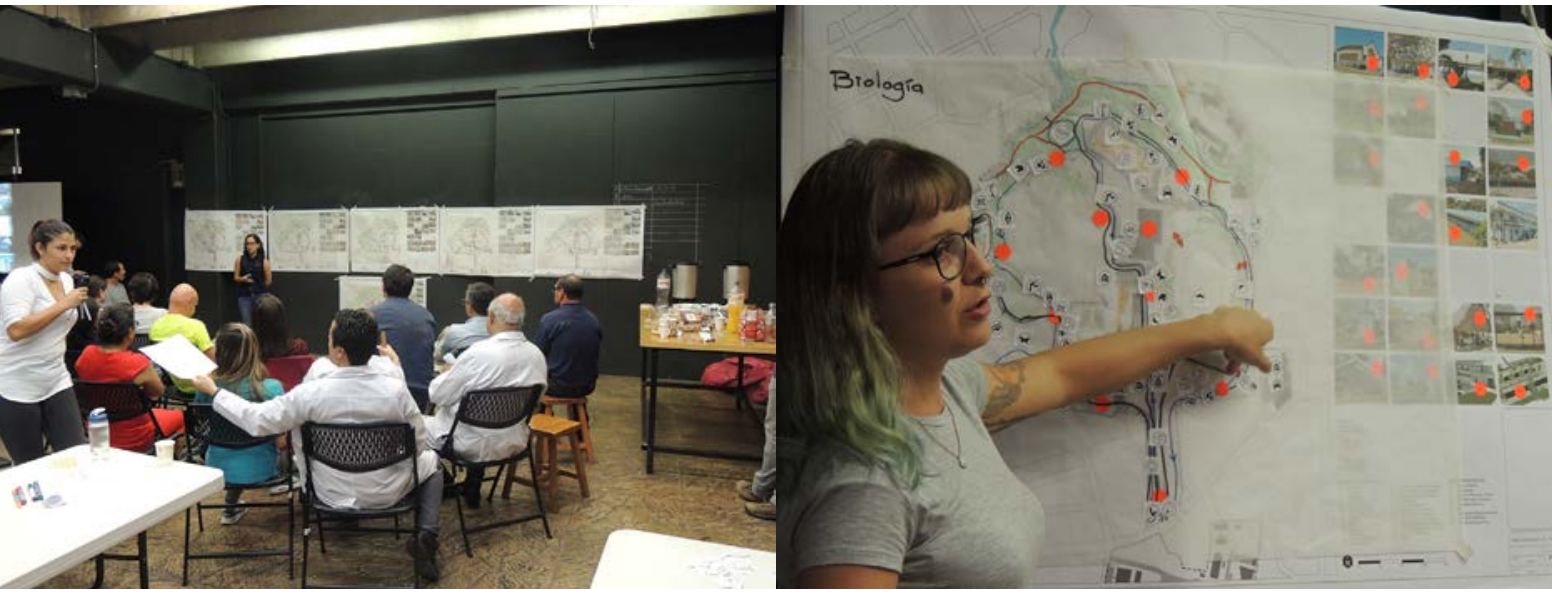

Figura 25. Procesos de trabajo. Exposición de trabajo realizado en el taller (centro). Fuente: Solano Monge, L (2017).

Figura 26. Exposición de propuesta Biología. Fuente: Chaves Hernández, G. (2017).

El primer taller con una duración de 3 horas fue de usuarios de la UCR y contó con la participación de 5 grupos divididos en Facultad de Odontología, Escuela de Biología, RAP, Foresta Universitaria y Escuela de Arquitectura, Unidad de Gestión Ambiental, Oficina de Servicios Generales, Rectoría, profesor invitado de Universidad Politécnica de Valencia y OEPI. En el segundo taller, con una duración de 7 horas, participaron vecinos, visitantes y colectivos relacionados con la Finca 3. Se organizaron 4 grupos representado a la Urbanización Buenos Aires, el colectivo Río Urbano, Movimiento de Conservación Ambiental Finca 3 y 4 y Probosque.

La lectura de todas estas herramientas no se dio de manera aislada, más bien, luego de la tabulación y análisis de los resultados obtenidos de las diferentes herramientas, fue posible tener una visión más clara de conjunto. 
Figura 27. Actividades realizadas por usuarios.

\section{Resultados de la participación}

Gracias a los cuestionarios, se pudo determinar cuáles actividades se realizaban con mayor frecuencia según la tipología de usuario (Figura 27). Se evidenció que más del $30 \%$ de todos los usuarios entrevistados visita el campus para caminar, mientras que la mayoría de los estudiantes asisten a clase deportiva. Se denotó la necesidad de incorporar una mayor cantidad de espacios donde fuera posible desarrollar prácticas pasivas, aumentando los lapsos de estadía, pues en general la mayoría de los entrevistados no permanecen en el sitio después de realizar su actividad (Figura 28).

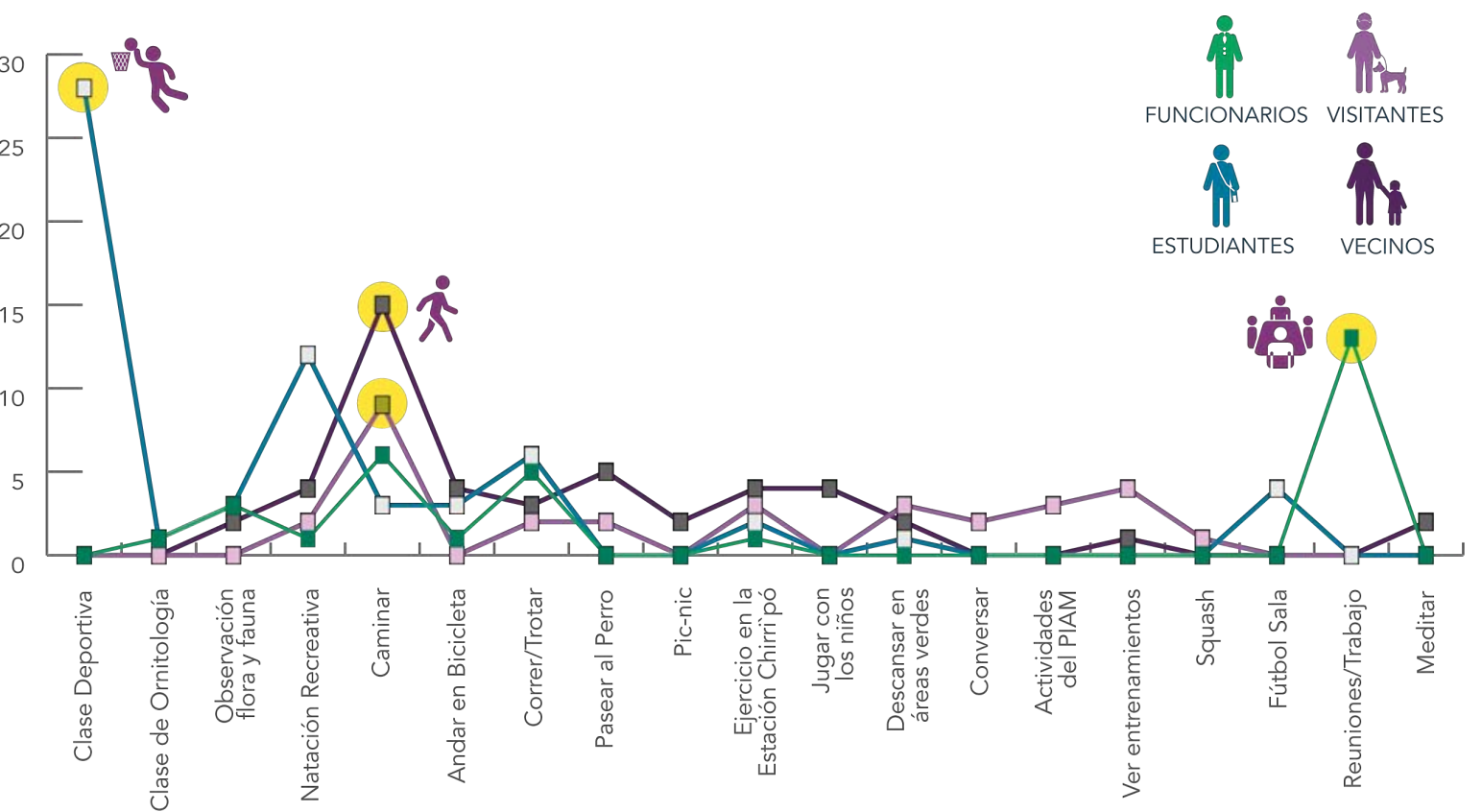

Figura 28. Permanencia en el sitio (derecha). Fuente: Chaverri Flores, L. et al. (2017). Propuesta de protección ambiental y desarrollo urbano paisajístico para Finca 3 Universidad de Costa Rica. San José, Costa Rica: Universidad de Costa Rica.

Figura 29 y 30. Valoración de elementos naturales. Fuente: Chaverri Flores, L. et al. (2017). Propuesta de protección ambiental y desarrollo urbano paisajístico para Finca 3 Universidad de Costa Rica. San José, Costa Rica: Universidad de Costa Rica.
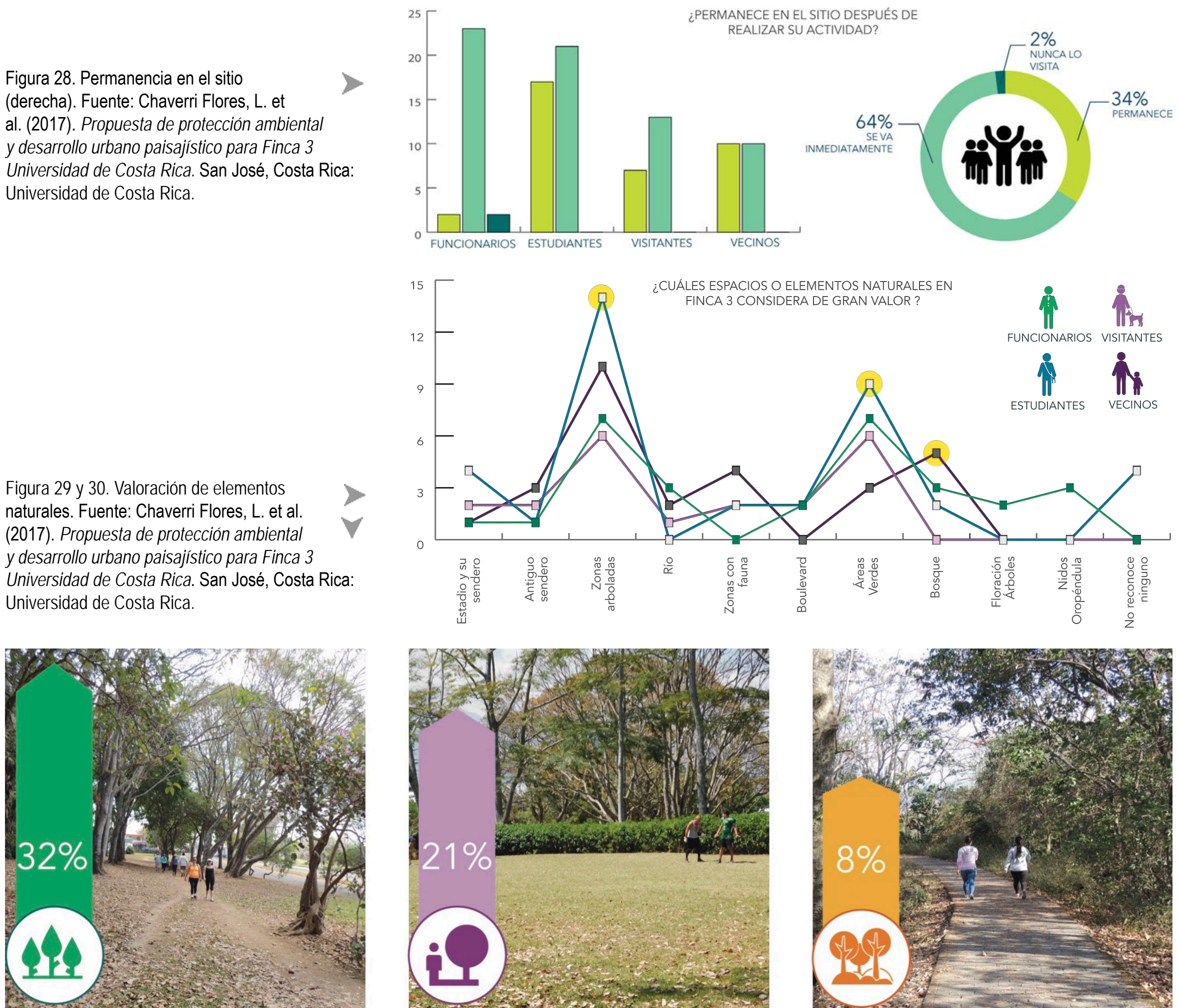
Figura 31 y 32. Valoración de espacios Finca 3. Fuente: Chaverri Flores, L. et al. (2017). Propuesta de protección ambiental y desarrollo urbano paisajistico para Finca 3 Universidad de Costa Rica. San José, Costa Rica: Universidad de Costa Rica

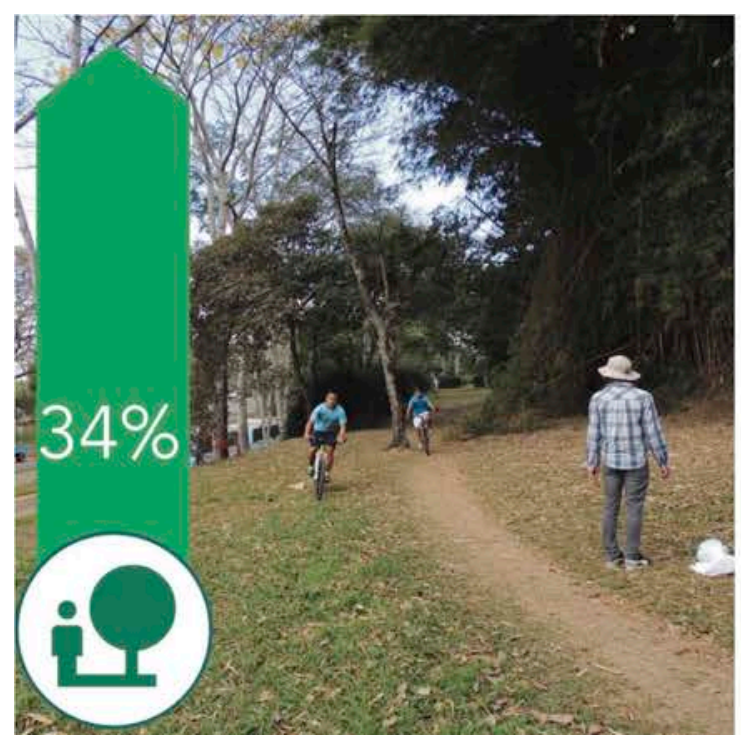

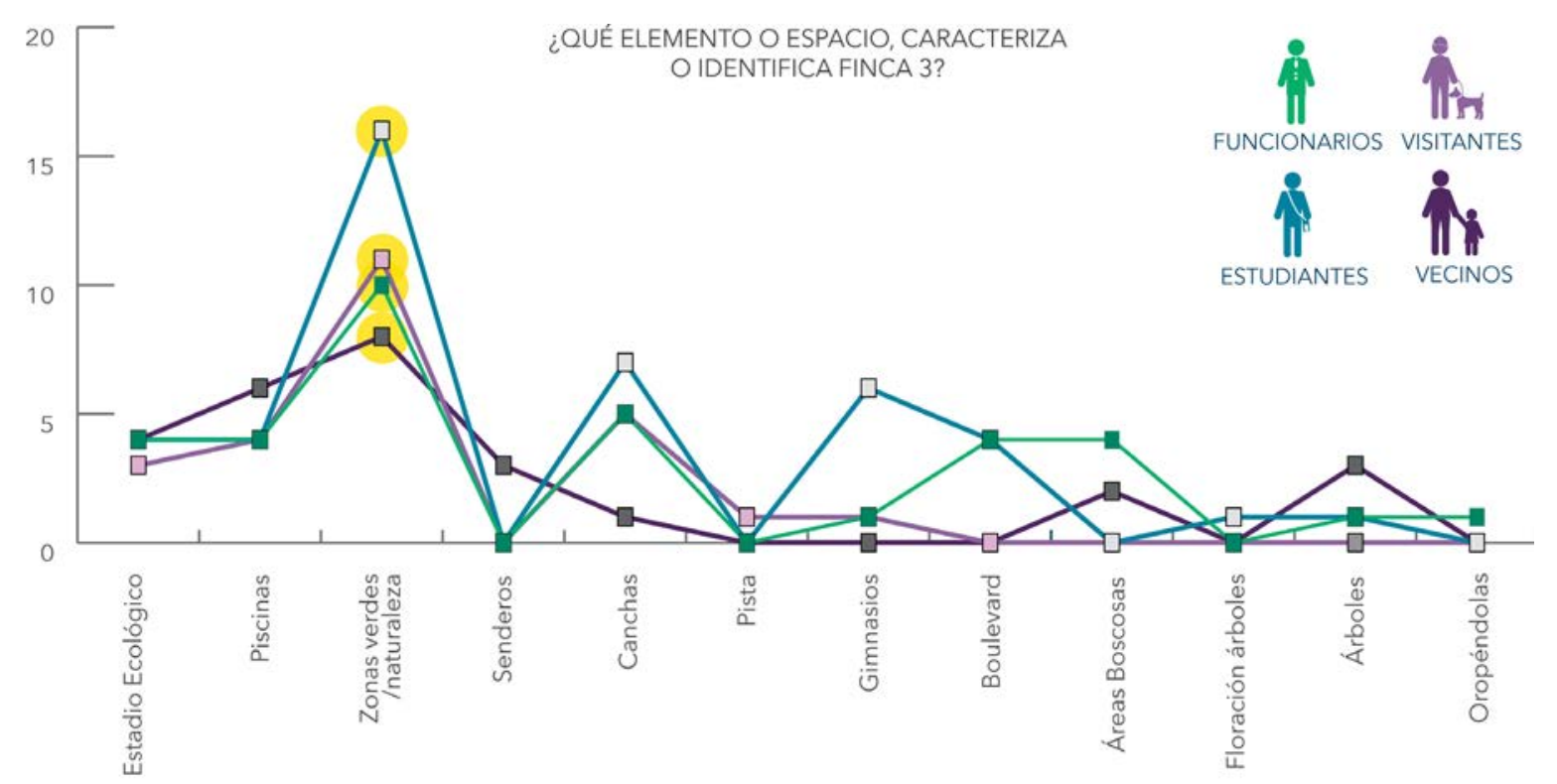
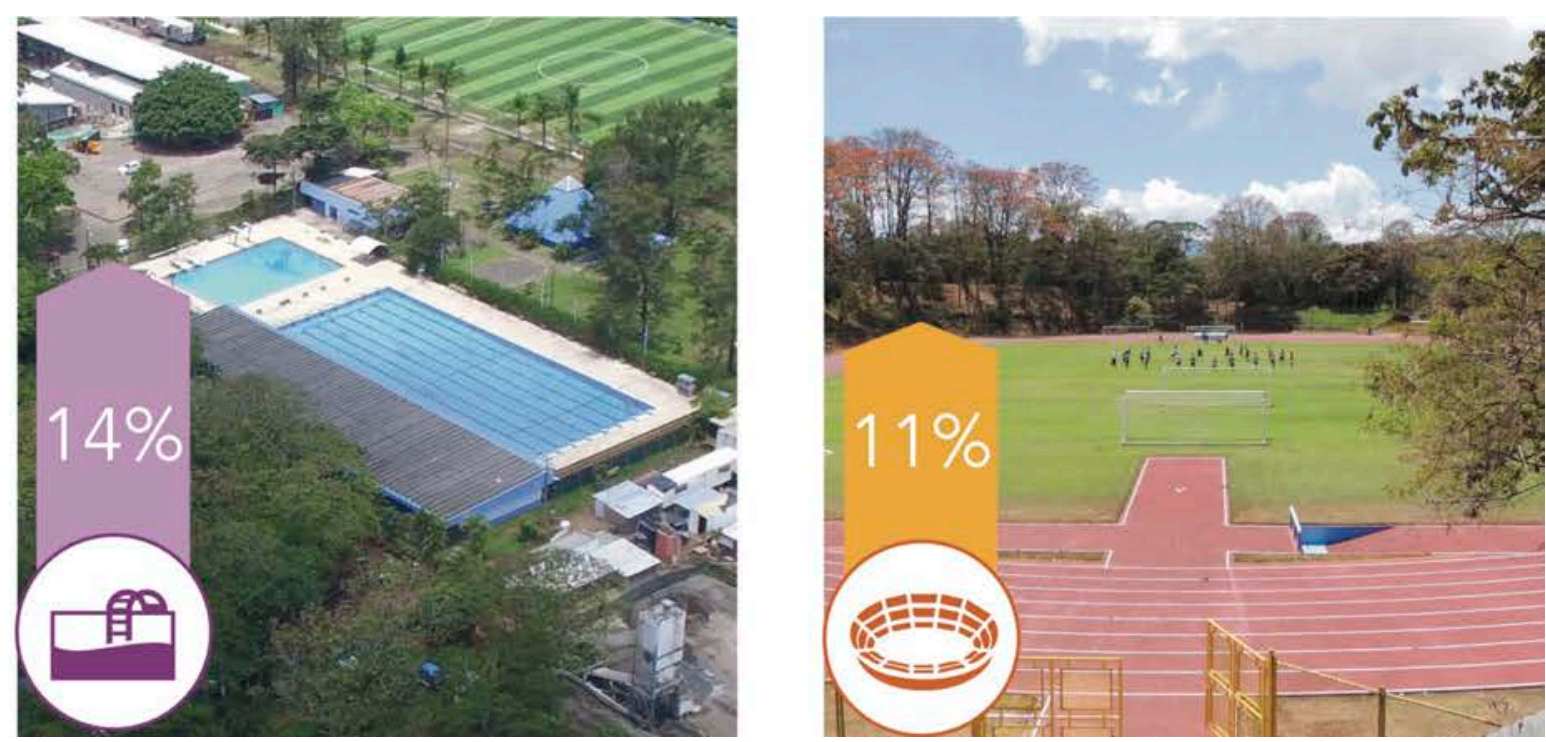

En cuanto a aspectos relacionados con el paisaje, la ecología y ambiente, en los talleres sobresalieron algunos lugares de avistamiento de aves, fauna y flora que luego se potenciaron en el diseño (Figuras 33a, 33b y33c). Se constató como los cuerpos de agua pasan desapercibidos entre los visitantes. En las encuestas, el $48 \%$ de los entrevistados desconoce la presencia del Río Torres y las quebradas en Finca 3 y el $56 \%$ nunca han visitado dichos cuerpos de agua. En los talleres, se recomendó el uso de biojardineras, una mejor canalización de las aguas pluviales y conexiones con lagunas de retardo para controlar el desfogue hacia los ríos o quebradas. Además, se detectaron los espacios naturales más valorados por los usuarios, sobresaliendo las zonas arboladas, áreas verdes y bosque (Figuras 29 y 30). Se identificaron los sitios que representan a la Finca 3 y le dan un sentido de pertenencia, pues son elementos trascendentales en su identidad, como lo son las zonas verdes y la naturaleza presente (Figuras 31 y 32). También se valorizaron las piscinas y el estadio ecológico. Por esta razón, es necesario proteger estas zonas valoradas por los usuarios con una propuesta paisajística que exalta dichas características. Además, en los talleres se trazaron los parches verdes que se deberían consolidar y reforzar. En el análisis de las fichas de evaluación, en la temática de vegetación, los proyectos con espacios arbolados con diseño más natural fueron los más escogidos.

En cuanto a la movilidad, se evidenció la inexistencia de un acceso peatonal fuerte y un sistema de paso continuo a través de toda la Finca. De los entrevistados, el $58 \%$ se moviliza peatonalmente, por lo que es indispensable mejorar las condiciones de las aceras y sendas. Además, en los talleres se demostró la necesidad de pasos cubiertos, considerando que 6 meses del año son lluviosos y se evidenció la necesidad de separar las sendas peatonales de las ciclovías. Los mapas de flujo (Figura 19) permitieron entender las dinámicas de movilidad y algunos recorridos creados espontáneamente por los usuarios, así como diferentes circuitos implantados. De esta forma, se estableció como criterio de diseño propiciar la formalidad de algunas sendas que son muy valoradas, pero no tienen las condiciones apropiadas. Se analizaron las características de las sendas consideradas más agradables para reforzar las cualidades espaciales, ambientales y paisajísticas de las sendas menos apreciadas. 


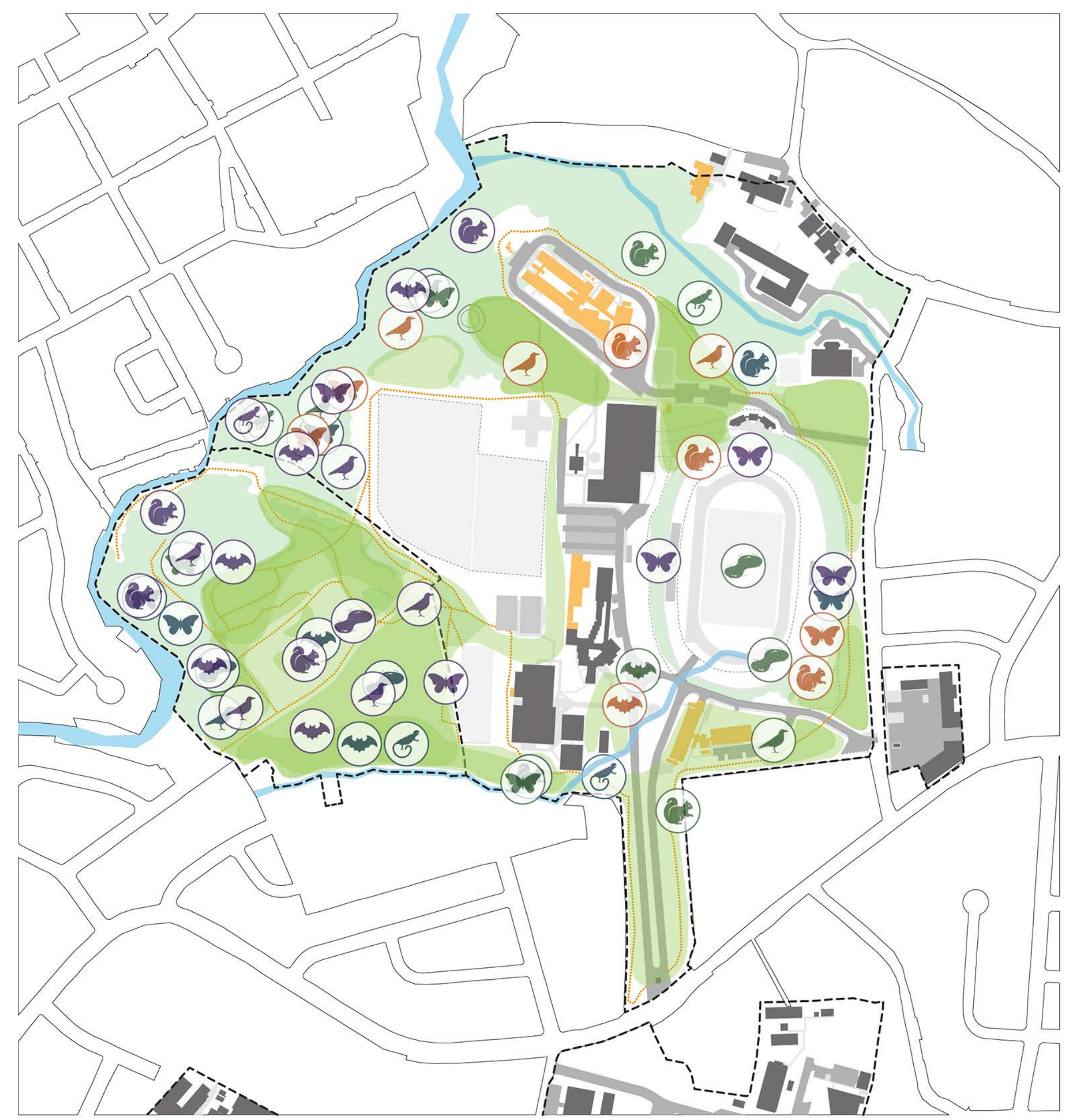

Figura 33a. Mapa síntesis de Ecología y Ambiente. Información obtenida en Taller de comunidad de vecinosy usuarios Finca 3. Fuente: Chaverri Flores, L.et al. (2017). Propuesta de protección ambiental y desarrollo urbano paisajistico para Finca 3 Universidad de Costa Rica. San José, Costa Rica: Universidad de Costa Rica.
A SIMBOLOGIA USADA PARA ELABORACIÓN DEL TALLER (ECOLOGIA Y AMBIENTE)

- Extensión propuesta de marches vegetales (Aagunas

(3) Aves

( Insectos

(4) Mamíferos

(5) Anfibios / Reptiles

Murciélagos
SIMBOLOGIA

$\begin{array}{ll}\text { Buenos Aires } & \text { Edificios nuevos } \\ \text { Río Urbano } & \text { Edificios existentes } \\ \text { MOCAF } & \text { Calles } \\ \text { Probosque } & \text { Aceras / Plazas } \\ & \text { Areas deportivas } \\ & \cdots \text { Senderos } \\ & \\ & \text { Parches vegetales } \\ & \text { - Vegetación existente } \\ & \text { Ríos / Quebradas }\end{array}$




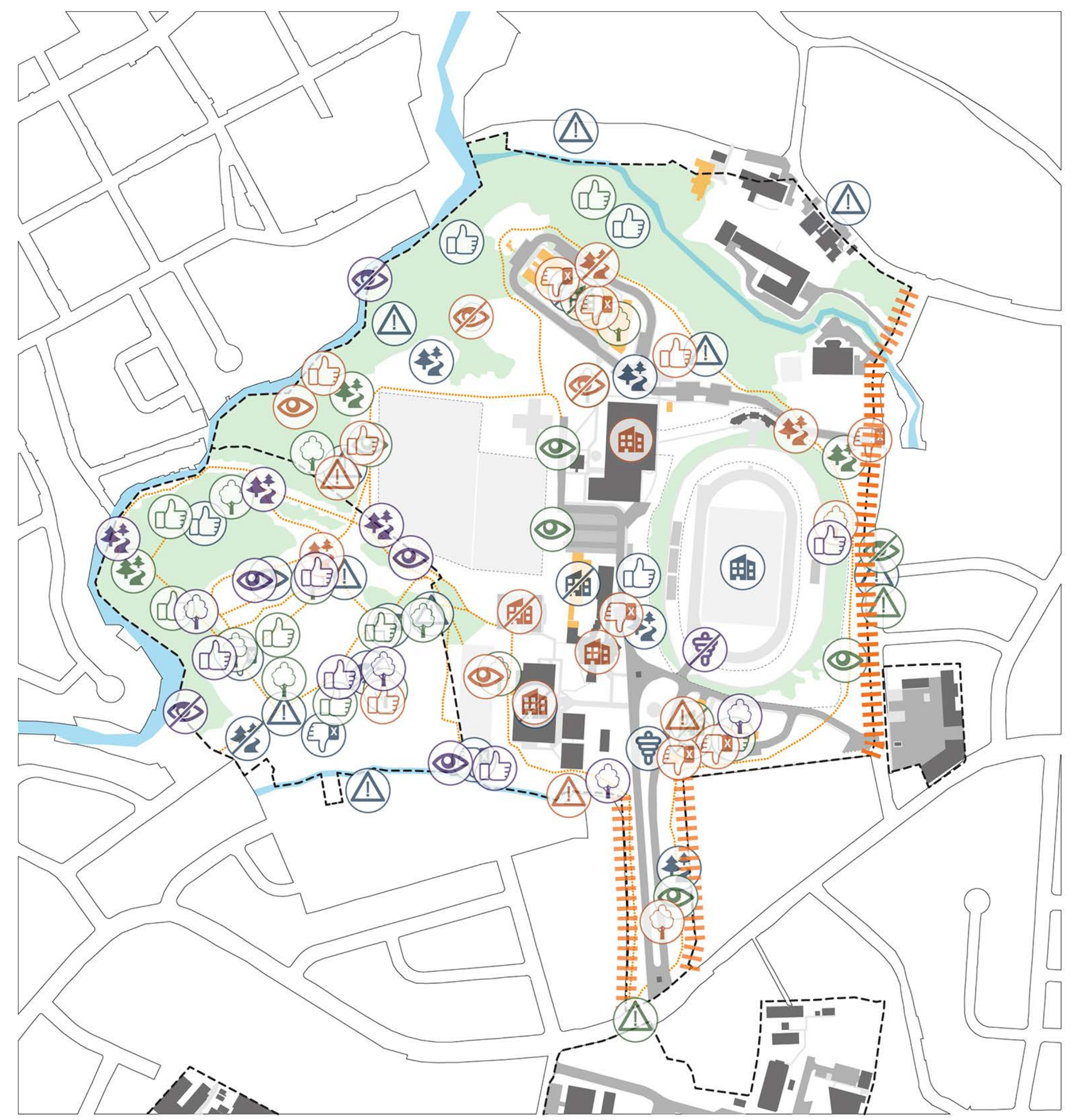

Figura 33b. Mapa síntesis de Paisaje.

Información obtenida en Taller de comunidad de vecinos y usuarios Finca 3. Fuente: Chaverri Flores, L.et al. (2017). Propuesta de protección ambiental y desarrollo urbano paisajístico para Finca 3 Universidad de Costa Rica. San José, Costa Rica: Universidad de Costa Rica.
A SIMBOLOGIA USADA PARA ELABORACIÓN DEL TALLER (PAISAJE)

IIII Tratamiento de bordes

(10) Lugares agradables

(8) Lugares desagradables

(3) (8) Arboles

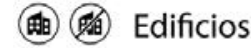

(*) Senderos

(i) (8) Esculturas

(2) (2) Puntos visuales
SIMBOLOGIA

- Edificios nuevos

- Edificios existentes

Calles

- Aceras / Plazas

Areas deportivas

.... Senderos

- Parches vegetales

- Vegetación existente

- Ríos / Quebradas 


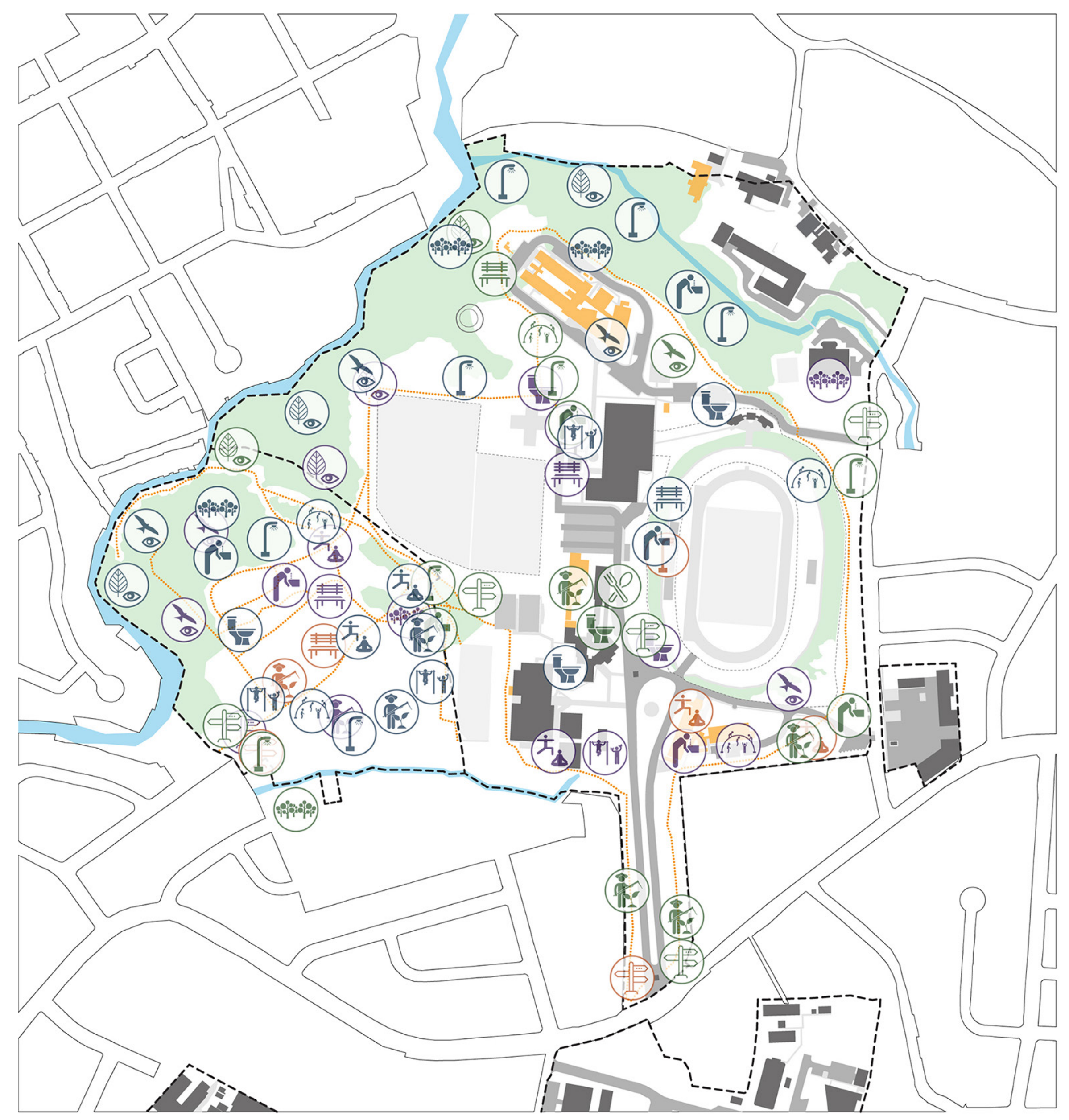

Figura 33c. Mapa síntesis de Servicios complementarios. Información obtenida en

Taller de comunidad de vecinos y usuarios Finca 3. Fuente: Chaverri Flores, L.et al. (2017). Propuesta de protección ambiental y desarrollo urbano paisajístico para Finca 3 Universidad de Costa Rica. San José, Costa Rica: Universidad de Costa Rica.
A SIMBOLOGIA USADA PARA ELABORACIÓN DEL TALLER (SERVICIOS COMPLEMENTARIOS)
(I-) Servicios Sanitarios
(1) Bebederos
(7.3. Zonas Pasivas
(8) Alimentación
(1) Iluminación
(i) Mobiliario
(iB) Señalización
(Aini) Juegos de niños
(3) Observación de flora
(2) Observación de fauna
- Espacios Temáticos
(7.) Producción Experimental

SIMBOLOGIA

- Edificios nuevos

- Edificios existentes

- Calles

- Aceras / Plazas

Areas deportivas

.... Senderos

$$
\begin{aligned}
& \text { - Parches vegetales } \\
& \text { - Vegetación existente } \\
& \text { Ríos / Quebradas }
\end{aligned}
$$


Respecto a los servicios complementarios, un $21 \%$ puntualizó la falta de espacios que posibiliten la compra de refrescos y comida, un 14\% anotó la necesidad de reforzar el mobiliario urbano y un $8 \%$ la necesidad de servicios sanitarios. En los talleres, los diferentes equipos indicaron ubicaciones idóneas para dichos servicios. Con respecto a la relación de los nuevos edificios con el entorno, un 50\% de las recomendaciones brindadas por los entrevistados sugieren la incorporación de elementos y zonas naturales a estas, con el objetivo de mantener la identidad natural que caracteriza a las Instalaciones Deportivas. Además, en los talleres se discutió la idea de minimizar el desarrollo de nuevos edificios e intentar ubicarlos en zonas deterioradas, como el plantel de transportes, en lugar de situarlos en áreas verdes consolidadas. Asimismo, se sugirió utilizar el mínimo de huella gracias a la implementación de parqueos subterráneos y desarrollo en altura. Con las fichas de evaluación, se concluyó que los entrevistados prefieren amplios espacios verdes con intervenciones mínimas y con montículos de césped como mobiliario predilecto. Respecto al programa, las áreas para el encuentro y descanso fueron las mejor valoradas.

También por medio de mapeos (Figura 20), se identificaron los espacios de mayor valor por su calidad ambiental y se evidenció la preferencia de la Zona Verde, el Boulevard y el Sendero Boscoso. Además, dichos espacios fueron caracterizados con cualidades de sensación de frescura por medio de la vegetación, amplitud, flexibilidad, privacidad y tranquilidad. En este caso, se constató que dos de los espacios predilectos coinciden con la ubicación de edificios, por lo que es muy importante trasladar las cualidades de estos a otros que puedan suplir estas características.

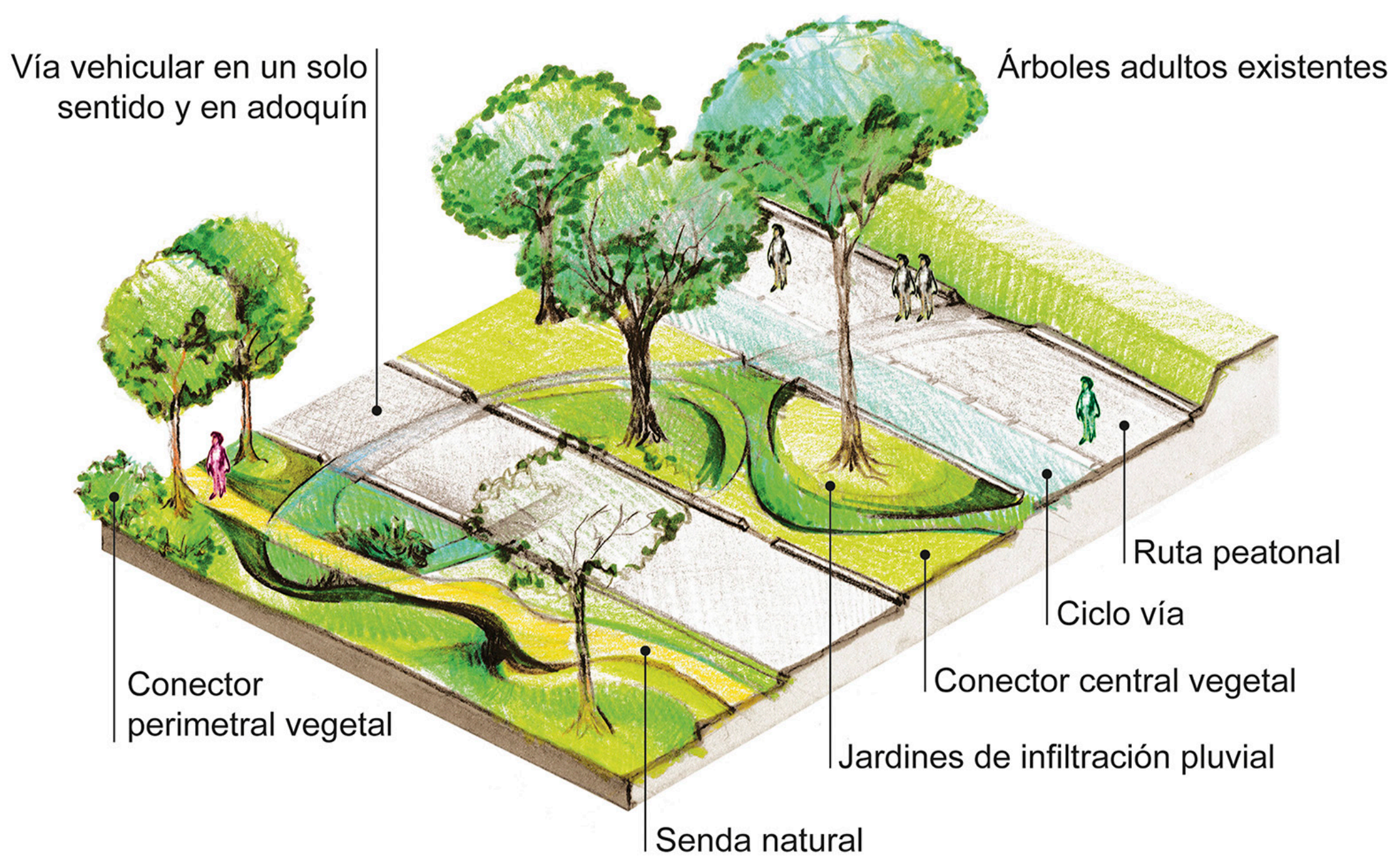

Figura 34. Isométrico de acceso a bulevard con jardines de infiltración pluvia. Fuente: Chaverri Flores, L. et al. (2017). Propuesta de protección ambiental y desarrollo urbano paisajístico para Finca 3 Universidad de Costa Rica. San José, Costa Rica: Universidad de Costa Rica. 


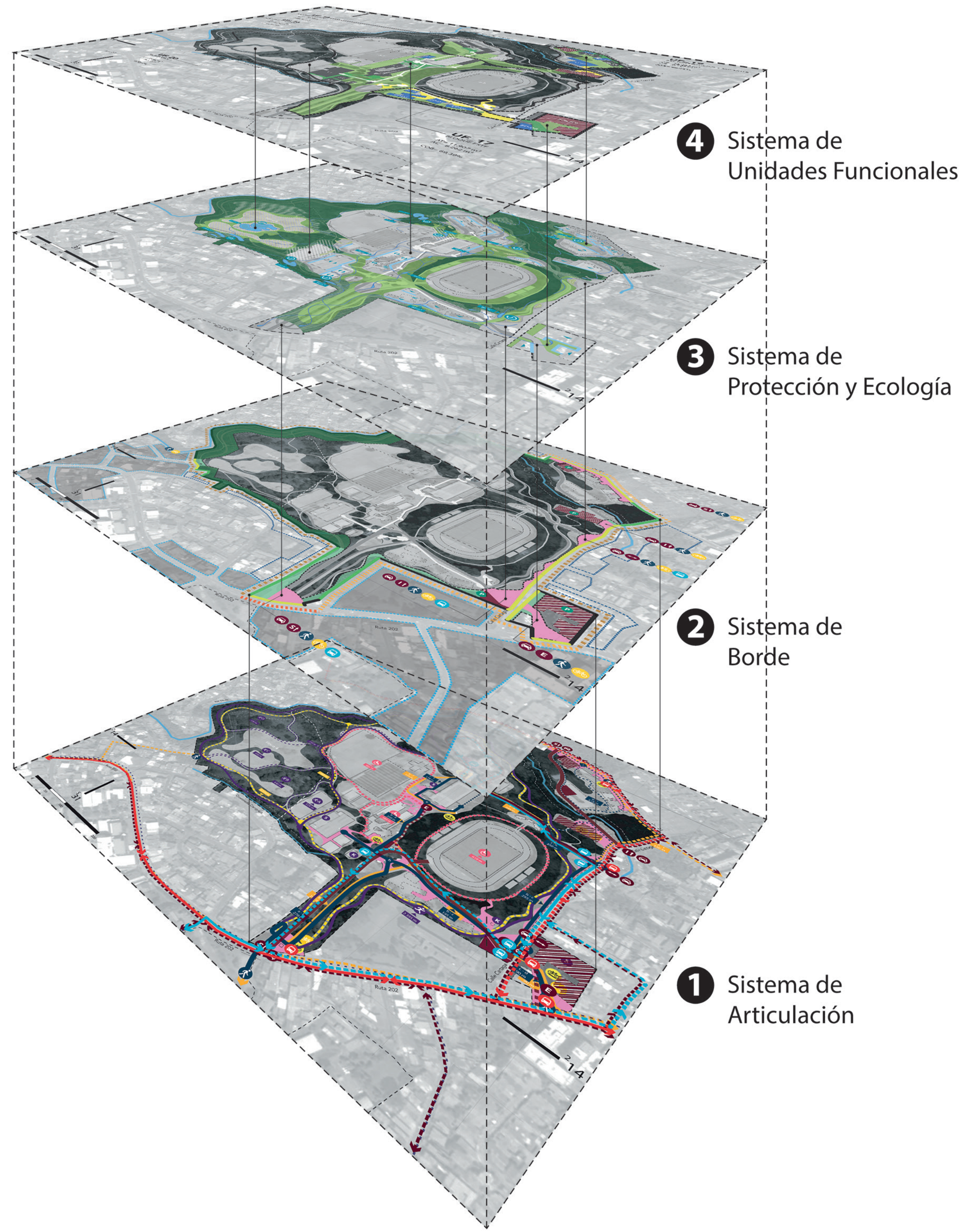

Figura 35. Propuesta de protección ambiental y desarrollo urbano paisajístico para Finca 3 Universidad de Costa Rica. San José, Costa Rica: Universidad de Costa

Fuente: Chaverri Flores, L. et al. (2017). 
Fue posible generar diferentes conclusiones orientadas al diseño, ya que a pesar de que cada grupo social tenía su propia visión de la Finca coincidian en la riqueza natural, en los talleres se evidenció la desarticulación existente entre oficinas y entidades ejecutoras de la Universidad, siendo una oportunidad para dialogar y conocer algunos proyectos que podrían contribuir en el mejoramiento de esta. Se aprovechó la experiencia de algunos profesionales que trabajan en la institución y de los vecinos que suelen recorrer a diario el espacio de estudio, generando una retroalimentación muy importante entre consultores y usuarios. El hacer participes del proceso de diseño 0 planificación territorial a diversos grupos, entre ellos los funcionarios y la comunidad, genera un antecedente para lograr una propuesta de planificación territorial del campus responsable e inclusiva.

El proceso de participación aportó de forma significativa al diagnóstico de la Finca y a la generación de la propuesta de diseño (Figura 39). Asimismo, aunadas a estas herramientas participativas, se utilizaron otras más convencionales como estudios topográficos, de escorrentías, botánicos, análisis de áreas, entre otros. De esta manera, nació la propuesta estableciendo los sistemas estructurantes y sus componentes en cuatro dimensiones: sistema articulador, de borde, de protección y conectores ecológicos paisajísticos y sistema de unidades funcionales (Figura 35). Este último se conformó por núcleos funcionales y espaciales caracterizados por edificaciones interrelacionadas a partir de un espacio común y vinculadas a otras unidades funcionales mediante un articulador principal, que en distintas escalas compone la sede central de la UCR. El sistema de articulación, por ejemplo, logró conectar los diferentes tipos de movilidades, utilizando como base algunos circuitos establecidos informalmente por los usuarios. También se resolvieron necesidades planteadas en los talleres como pasos techados, ciclovías y rutas peatonales diferenciadas, así como la incorporación de montículos como parte del mobiliario urbano, entre otros (Figura 34). Dentro de este sistema, el componente peatonal consiste en una red que comunica los accesos peatonales perimetrales con una serie de plazas en el medio de los edificios y un conector hacia el sur que permite conectarse con los otros territorios de la UCR (Figuras 36, 37 y 38).

Por otra parte, en el sistema de protección y ecología, se incorporaron una serie de estrategias para darle protagonismo a los cuerpos de agua como los ríos, invisibilizados por los usuarios. Se establecieron de esta manera canales de agua, jardines pluviales, canales y lagunas de retardo dentro del componente hídrico, que muestran el recorrido natural del agua al río y permiten un manejo adecuado del agua de lluvia acorde a la topografía (Figura 38).

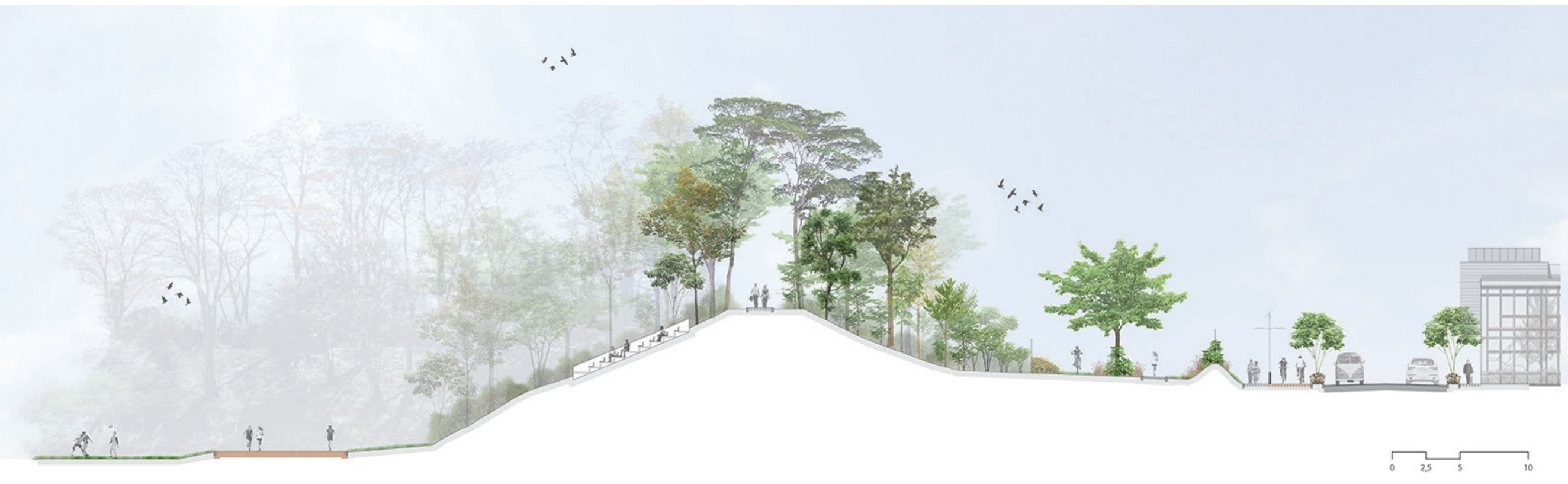

Figura 36. Sección desde Boulevard externo hasta Estadio ecológico. Fuente: Chaverri Flores, L. et al. (2017). Propuesta de protección ambiental y desarrollo urbano paisajístico para Finca 3 Universidad de Costa Rica. San José, Costa Rica: Universidad de Costa Rica. 


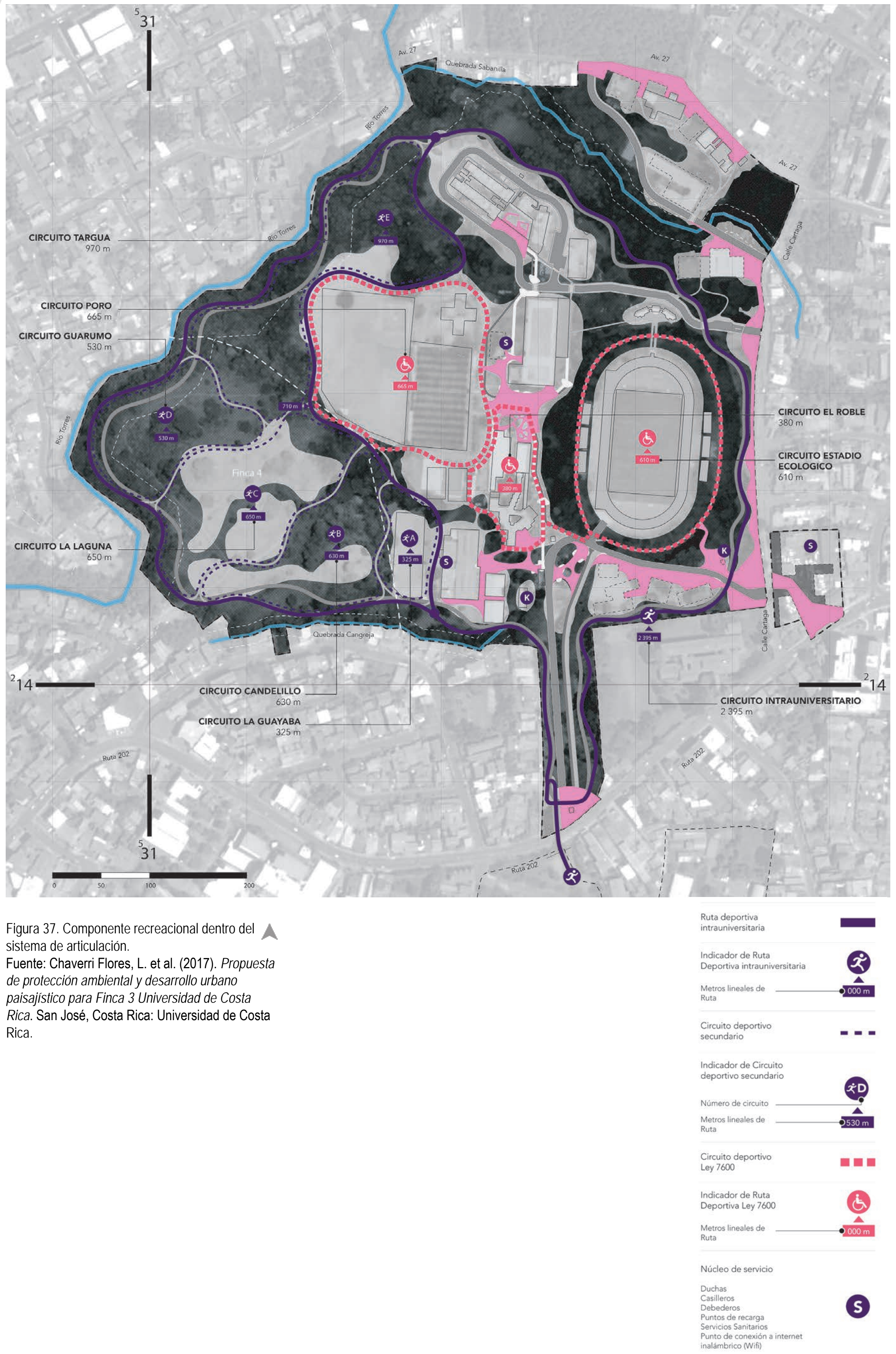




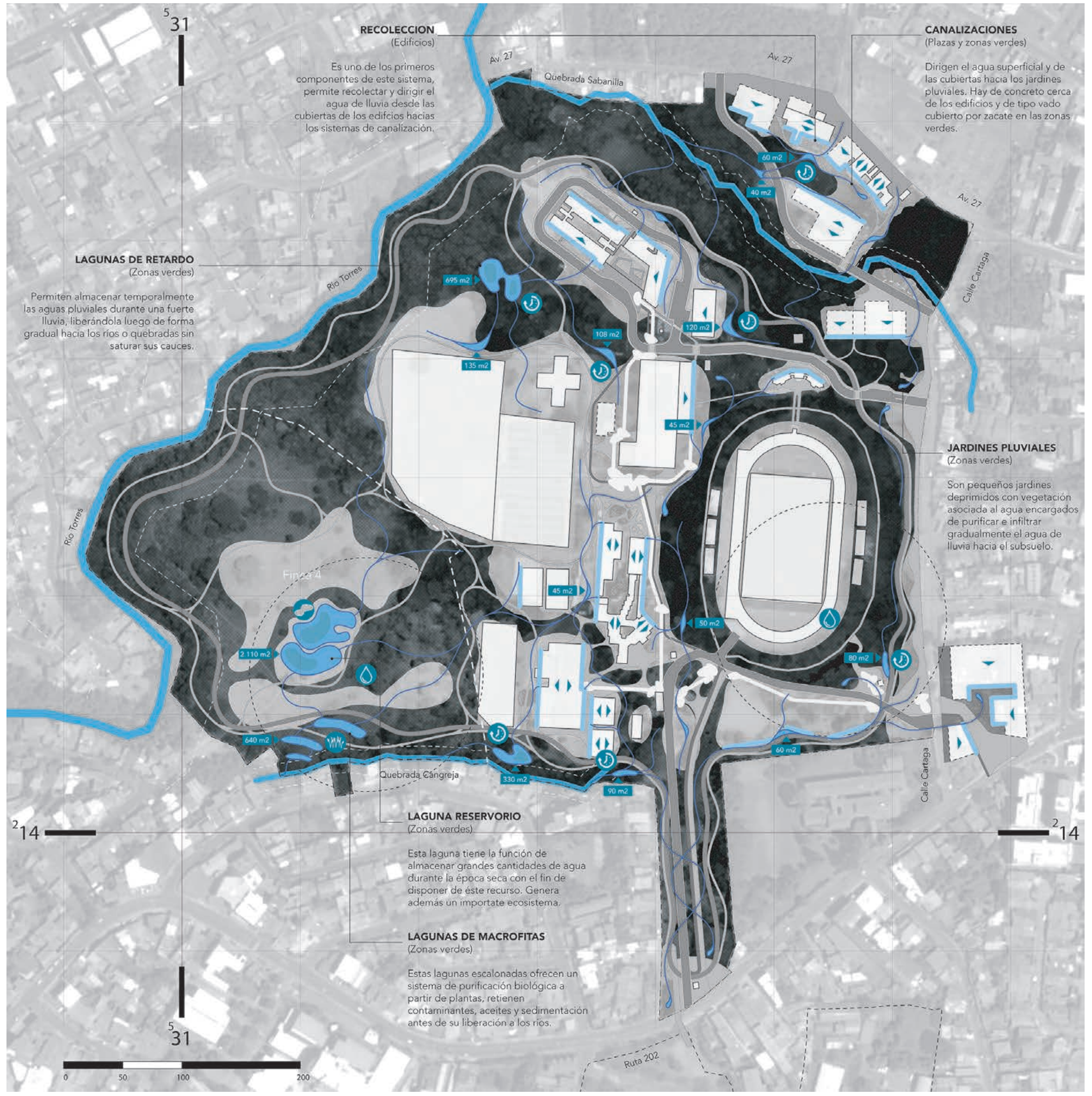

Figura 38. Componente hídrico dentro del

sistema Ecología y paisaje. Fuente: Chaverri

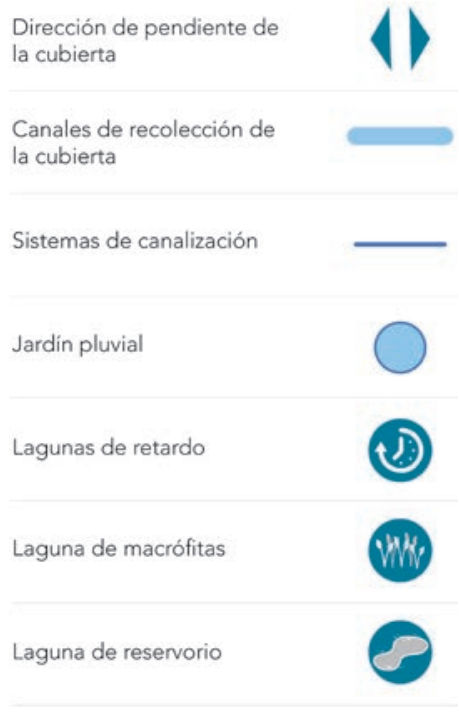

Flores, L. et al. (2017). Propuesta de protección

ambiental y desarrollo urbano paisajístico para

Finca 3 Universidad de Costa Rica. San José,

Costa Rica: Universidad de Costa Rica. 


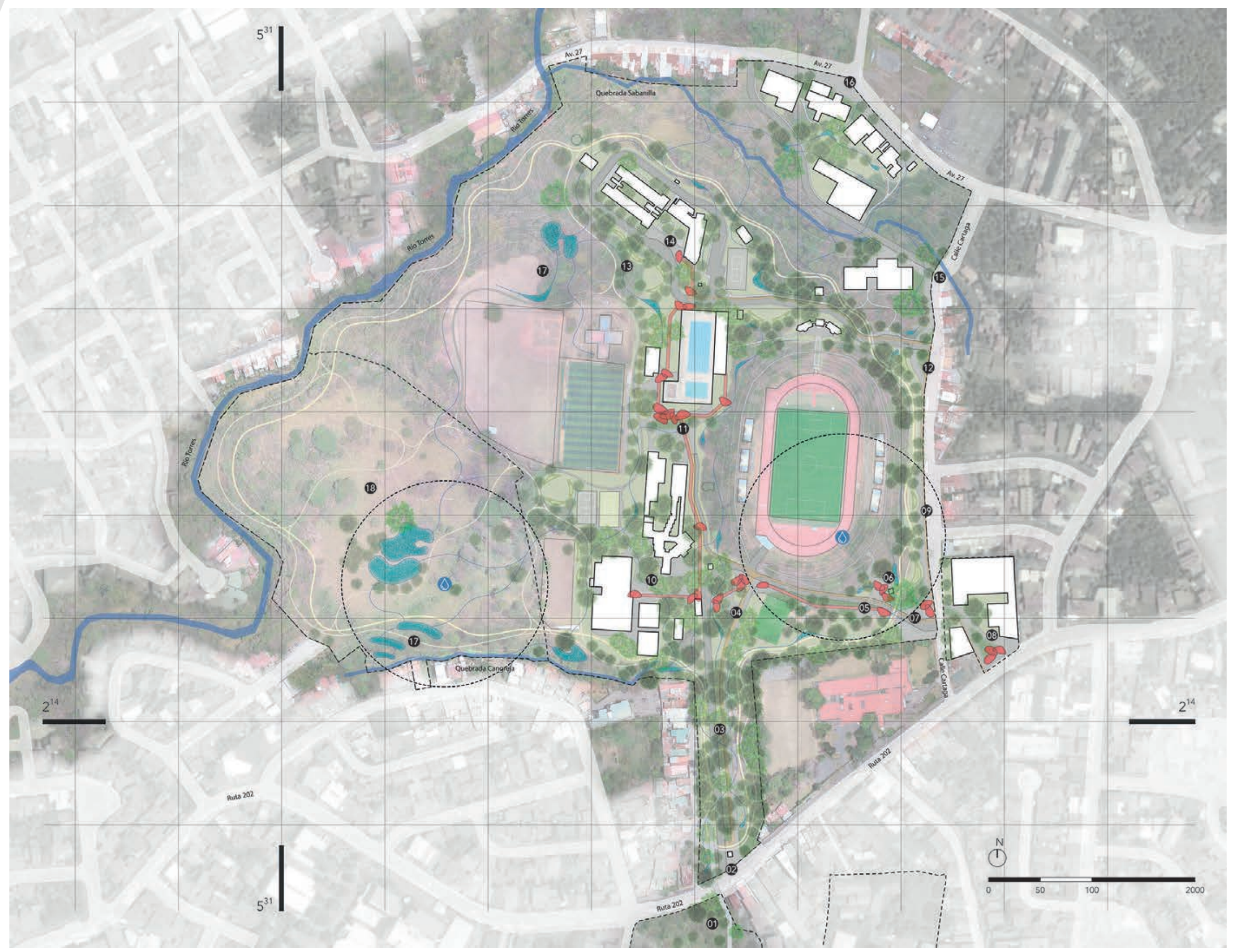

Figura 39. Propuesta final. Fuente: Chaverri

(1) Conector elevado entre Finca 2

Flores, L. et al. (2017). Propuesta de protección

ambiental y desarrollo urbano paisajístico para

Finca 3 Universidad de Costa Rica. San José,

(22) Plaza de acceso Cortez amarillo

Costa Rica: Universidad de Costa Rica.

(3) Boulevard de acceso

(4) Plaza del Corredor

(6) Plaza Poponjoche

06 Plaza Estadio Ecológico

(7) Plaza Higuerón

08 Plaza de Acceso

09 Nuevo boulevard de borde

(10) Plaza del deporte

(1) Plaza Ecología

(12) Acceso a Odontología

(13) Sistema de borde Odontología

(14) Plaza Odonto

(15) Nuevo acceso a bloque de

(16) Plaza Libertad

(17) Sistemas hídricos de canales, Finca 4: destinada a zonas de protección de ecosistemas
riparios, charrales y bosque

riparios, charrales y bosque
secundario, manejo hídrico,

secundario, manejo hidrico,
senderos deportivos y espacios 


\section{Resultados y discusión}

\section{Sobre los actores}

En los diferentes proyectos, fue posible apreciar como siempre existe un ente contratante, un equipo profesional contratado y usuarios que utilizarían los proyectos una vez que fueran construidos. En la mayoría de los casos, los procesos participativos fueron impuestos por el ente contratante, buscando lograr una conciliación entre los usuarios y el proyecto (Plaza de Armas, Conjunto Habitacional Iquique); mientras que, en el caso del proyecto de Costa Rica, el proceso participativo fue una iniciativa del equipo profesional (Tabla 1).

\begin{tabular}{|c|c|c|c|c|}
\hline \multicolumn{5}{|c|}{ Resumen de estudios de casos analizados } \\
\hline & "Place d'Armes" & $\begin{array}{l}\text { Vivienda colectiva- } \\
\text { Iquique }\end{array}$ & "Le Quais de Bordeaux" & Finca 3. UCR \\
\hline Fecha & $\begin{array}{l}2013 \text { (Proceso } \\
\text { participativo) }\end{array}$ & 2004 & $2000-2009$ & 2017 \\
\hline Área & $48.000 \mathrm{~m}^{2}$ & $5722 \mathrm{~m}^{2}$ & $\begin{array}{l}4.5 \mathrm{~km} \text { de largo x } 80 \\
\mathrm{~m} \text { ancho. } 360000 \mathrm{~m}^{2} . \\
36 \mathrm{~h}\end{array}$ & $234.200 \mathrm{~m}^{2}$ \\
\hline Tipo de proyecto & $\begin{array}{l}\text { Rediseño urbano y } \\
\text { paisajístico }\end{array}$ & $\begin{array}{l}\text { Vivienda colectiva de } \\
\text { interés social }\end{array}$ & $\begin{array}{l}\text { Rediseño urbano y } \\
\text { paisajístico }\end{array}$ & $\begin{array}{c}\text { Propuesta de protección } \\
\text { ambiental y desarrollo } \\
\text { urbano paisajístico }\end{array}$ \\
\hline Ente contratante & $\begin{array}{l}\text { (URBAT) de la } \\
\text { Municipalidad }\end{array}$ & $\begin{array}{c}\text { Gobierno de Chile. } \\
\text { Programa Chile Barrio }\end{array}$ & $\begin{array}{l}\text { Communauté urbaine de } \\
\text { Bordeaux } \\
\text { La "mairie de Bordeaux" }\end{array}$ & $\begin{array}{l}\text { Universidad de Costa } \\
\text { Rica }\end{array}$ \\
\hline Profesionales & $\begin{array}{l}\text { Instituto G2C-HEIG-VD } \\
\text { (profesionales contratados } \\
\text { para proceso paricipativo) }\end{array}$ & ELEMENTAL & "Corajoud Atelier" & $\begin{array}{l}\text { Equipo profesional } \\
\text { dirigido por Laura } \\
\text { Chaverri }\end{array}$ \\
\hline Usuarios & $\begin{array}{c}\text { Población de la zona, } \\
\text { turistas y público en } \\
\text { general }\end{array}$ & 93 familias & $\begin{array}{l}\text { Población de la zona, } \\
\text { turistas y público en } \\
\text { general }\end{array}$ & $\begin{array}{c}\text { Población universitaria, } \\
\text { vecinos y visitantes }\end{array}$ \\
\hline Herramientas & $\begin{array}{l}\text { Encuesta en línea } \\
\text { Encuesta cualitativa } \\
\text { Exposición de fotografías } \\
\text { Concurso de fotografía } \\
\text { artística } \\
\text { Talleres } \\
\text { Taller de maquetas }\end{array}$ & $\begin{array}{l}\text { Votaciones } \\
\text { Talleres } \\
\text { Fotomontajes } \\
\text { Trazado de casa } \\
\text { Dibujos y propuestas } \\
\text { escritas } \\
\text { Visitas de obra } \\
\text { Encuesta }\end{array}$ & $\begin{array}{l}\text { Reuniones } \\
\text { Diálogo } \\
\text { Apropiación espontánea } \\
\text { Consejos de barrio } \\
\text { Adhesión espontánea de } \\
\text { habitantes }\end{array}$ & $\begin{array}{l}\text { Cuestionarios } \\
\text { Mapas de flujo } \\
\text { Fichas de evaluación } \\
\text { Talleres participativos } \\
\text { Apropiación espontánea }\end{array}$ \\
\hline
\end{tabular}


En los distintos proyectos se nota como el papel del gobierno es muy importante para la ejecución de estos, ya sea por actuar como el ente contratante (Plaza de Armas, Conjunto Habitacional, Muelle de Bordeaux), o por la incorporación de políticas públicas y reglamentos a analizar 0 acatar. Sin embargo, sobresale que, aunque estos últimos parecen ser inamovibles, gracias a la participación y el análisis de los reglamentos establecidos, es posible generar cambios paradigmáticos como lo hizo el proyecto de vivienda en Iquique, donde por primera vez se aceptó realizar proyectos de vivienda sin dormitorios para que en una etapa posterior cada usuario pudiese incorporarlos según sus necesidades.

Desde el punto de vista de los profesionales, destaca que se conformaron equipos multidisciplinarios. El Instituto G2C-HEIG-VD, contratado para el proceso participativo en el proyecto en Yverton, está dirigido por un especialista en gobernanza territorial y dentro del equipo trabajan hidrólogos, ingenieros, urbanistas, entre otros. Para los talleres, se contó con la participación de estudiantes de arquitectura, paisaje y urbanismo, así como profesionales en esa área. En el caso de Aravena y su equipo, a pesar de que la mayoría del mismo está compuesto por arquitectos, se denotó una participación con otros profesionales del Programa Chile Barrio. Es interesante acotar que Aravena fundó ELEMENTAL, en 1994, junto con Andrés lacobelli, ingeniero industrial, máster en políticas públicas y en ingeniería de transporte, partiendo desde un inicio con una visión multidisciplinaria. En el caso del equipo de Corajoud, este cuenta con paisajistas, arquitectos, diseñadores de fuentes, entre otros. Finalmente, en el caso de las Instalaciones Deportivas, dentro del equipo participaron biólogos, arquitectos, paisajistas y diseñadores. Vale la pena rescatar que los talleres tuvieron el aporte de gran cantidad de profesionales de diversas disciplinas.

Asimismo, destaca que la estrategía participativa no se enfoca o limita a solicitarle a la población realizar un proyecto de diseño, por el contrario, las estrategias de participación fueron planificadas muy detalladamente por los equipos consultores con objetivos concretos que ayudacen al profesional a realizar su propuesta e interpretar los resultados. Se observa que en el proceso se toma en cuenta tanto a los individuos como a las comunidades y se procura comprender los modos de vida de algunos grupos específicos. Por ejemplo, en el proyecto de Aravena se dividieron algunas reuniones según los grupos sociales o étnicos, evidenciando algunas prácticas culturales diversas entre los mismos.

\section{Sobre las herramientas, métodos y procesos}

Se observaron variedad de herramientas como talleres participativos, concursos de fotografías, mapas de flujos, apropiación espontánea o encuestas. Estos métodos ayudaron a solucionar preguntas concretas de diseño, por lo que la planificación de las actividades resultó indispensable. Los cuestionarios y votaciones generaron apreciaciones más cuantitavivas, mientras que los talleres, concursos, mapas de flujo y fotomontajes concibieron resultados más cualitativos.

En los distintos proyectos se optó por el uso de la encuesta cuantitativa, tanto en línea como impresa. Joerin (2017) en el Congreso Mundial de Diseño desarrollado en Montreal, reflexionó sobre la eficacia de la encuesta en línea. Una de las preguntas que hizo el ponente fue: ¿la encuesta en línea puede ser suficiente? Para el profesor, con esta herramienta es posible hacer un diagnóstico y muestra de una representación estadística. Es posible mejorar el proyecto y, al ser un ejercicio individual, genera poco conflicto. Sin embargo, con esta herramienta no es posible generar soluciones o compromisos y no contribuye a la apropiación del proyecto. Para Joarin, la encuesta en línea ayuda a los diseñadores, pero se debe tener un trabajo de interpretación que se puede alejar de la objetividad.

Por lo tanto, la elaboración de las encuestas tanto cualitativas como cuantitativas deben ser estudiadas minuciosamente para poder alcanzar un objetivo con su desarrollo. Desde el punto de vista del diseño del espacio público, resulta fundamental poder conocer los gustos de los usuarios. Sin embargo, se debe tener cuidado de no excluir a las minorías y no solo beneficiar a lo que Bourdieu llama la "clase dominante" que posee diferentes gustos y estilos de vida (Álvarez Sousa, 1996, p. 154). 
Para Adrián Scribano y Angélica De Sena (2009), con la auto-etnografía "el investigador tiene el privilegio y la responsabilidad de ser sujeto y objeto (...). Desde la autoetnografía, se contra argumenta que el desafío es utilizar la propia experiencia para ampliar la compresión sobre lo social" (p. 6). Si el fenómeno social que se quisiera comprender son las relaciones sociales para el diseño del espacio público o privado, ¿qué tan beneficioso es que el investigador y, en este caso diseñador, sea también objeto y sujeto?, ¿Cómo potenciar un equilibrio entre la experiencia propia y la de otras personas que utilizan el espacio público estudiado? Para el proyecto de Finca 3, fue interesante que gran parte del grupo de profesionales coincidentemente eran usuarios habituales de las Instalaciones Deportivas. Esto permitió una visión más cercana de la problemática, no obstante, esta condición particular no era suficiente para comprender las necesidades de los diversos grupos que frecuentan dicho espacio, por lo que con el fin de obtener resultados más objetivos, esta experiencia personal se complementó con otros análisis y las herramientas participativas.

La observación de los usos espontáneos realizados por los usuarios en el lugar es otra innovadora herramienta. Se nota que esta contribuyó e influyó el diseño de la propuesta final, pues permitió a los diseñadores, en el caso Finca 3, establecer circuitos y, en el caso de Corajoud establecer las actividades programáticas. Por lo tanto, según el objetivo se debe elegir una o varias herramientas. Los talleres, aunque requieren de mucho trabajo de preparación, se mostraron como una herramienta muy eficaz para la confrontación de ideas y búsqueda de solución colectiva. Por supuesto, dentro de la diversidad de usuarios van a surgir contradicciones y opiniones encontradas. Será entonces el deber de los consultores de utilizar estas contradicciones como un insumo que genere oportunidades y retos para el diseño. Finalmente, la interpretación cruzada es fundamental para lograr una visión global de todos los procesos y la toma de decisiones.

\section{Conclusiones: resultados de la participación}

En general, ha existido un vacío en la formación social de los diseñadores a nivel universitario. Su educación muchas veces se enfoca más en el objeto a diseñar que en el análisis de los usuarios y sus formas de vida. De la misma forma, la formación interdisciplinaria es vital para que todos los profesionales puedan comprenderse y trabajar en equipos.

Luego de analizar diferentes estudios de caso, queda claro que no es posible universalizar el diseño y que las condiciones climáticas, culturales y formas de vida de sus usuarios determinan la toma de desiciones proyectuales. Por lo tanto, es imprescindible el conocimiento de los estilos de vida de cada comunidad y las particularidades de los usuarios, pues estas difícilmente se pueden encontrar en los libros o mediante recetas universalistas, por lo que el contacto entre el diseñador y el usuario por medio de herramientas participativas es esencial para potenciar un diseño adecuado. Las experiencias analizadas corresponden a lo que Lyotard bautizó como "pequeñas historias", que ayudaron a los diseñadores a generar su propio camino con base en su objeto de diseño.

La idea del arquitecto o diseñador sabelotodo ha cambiado drásticamente. Por ejemplo, en el Conjunto Habitacional de lquique, ELEMENTAL ideó un proyecto que pudiera terminarse posterior a la entrega de las viviendas, dejando una gran responsabilidad a las familias. No obstante, el trabajo profesional para prever diferentes opciones y la incorporación del diseño incremental es otra novedad poco pensada entre los diseñadores tradicionales.

La participación permite proyectos más transparentes, que de alguna forma "restringen acciones de corrupción en la administración de un proyecto" (Márquez, 2011, p. 19). Por medio de estos procesos de participación, es posible conciliar intereses, aspiraciones, visiones, así como problemáticas y potencialidades del sitio identificadas por los usuarios y grupos interesados. Se generan así oportunidades de aprendizaje tanto para el equipo consultor como para los participantes. Además, la incorporación de procesos participativos permite al investigador tomar decisiones más acertadas en 
etapas posteriores. Esto en la medida en que la información recolectada sea útil y pertinente; de aquí la importancia de elegir y aplicar correctamente las herramientas de consulta, ya que las contribuciones de los usuarios pueden validar, así como guiar a nuevas líneas de investigación no exploradas.

Es importante resaltar que en todos los casos, la participación tiene una repercusión importante en la toma de decisiones relacionadas con el diseño, pues más allá de este, estimula nuevas alianzas y complicidades en la forma de vida y en las relaciones entre los usuarios y actores involucrados. Por ejemplo, en Iquique estos procesos promovieron la interacción de los vecinos y la conformación de espacios comunes que permitirían la sociabilización y modificarían o conservarían conductas sociales tradicionales. En el muelle de Bordeaux fue posible generar una nueva cultura urbana y profesional (Godier \& Mazel, s.f., p.10). En este sentido, ya no se trata de "decorar" el espacio público con servicios aislados como fuentes, iluminación, entre otros, sino de ir más allá y velar por la felicidad y el bienestar de la diversidad de grupos que componen la ciudad. Para Guy Tapie (2007), con el proyecto del muelle de Bordeaux fue posible eliminar las barreras sociales y muchas categorías de personas se cruzan y se mezclan potenciando el contacto de familias, deportistas, turistas, entre otros (p. 20). Además, gracias al tranvía que desemboca a lo largo del parque lineal, cohabitan mundos opuestos: "rive gauche", la burguesía, con "rive droite" lo popular (p. 44).

Finalmente, se aprecia como parte de los insumos generados a través de la participación pasarían desapercibidos con solo un diagnóstico físico-espacial de la zona. Los diseñadores son esenciales en los procesos de construcción de los objetos proyectuales y estos, con el apoyo de los usuarios y un ente contratante visionario, son capaces de transformar una plaza en desuso en un lugar de bienestar para recuperar el deseo de vivir, experimentar un territorio o reconquistar un río.

\section{Referencias bibliográficas}

Alvarez Sousa, A. (1996). El Constructivismo estructuralista: La teoría de las clases sociales de Pierre Bourdieu. Reis (75), 145-172.

Aravena, A., y Lacobelli, A. (2016). ELEMENTAL, Manual de vivienda incremental y diseño participativo. Alemania: Jatje Cantz.

Chaverri Flores, L., Chaves Hernández, G., Solano Monge, L., Badilla Alvarado, K., Corrales Fallas, N., Solera Porras, S., . . Barquero Barahona, M. (2017). Propuesta de protección ambiental y desarrollo urbano paisajístico para Finca 3 Universidad de Costa Rica. San José, Costa Rica: Universidad de Costa Rica.

Communauté urbaine de Bordeaux y Mairie de Bordeaux. (mayo 2009). Dossier de presse. Les quais rive gauche a Bordeaux. Recuperado de http://www.bordeauxmetropole.fr/Espace-presse/L-inauguration-des-quais-rive-gauche

Commune d'Yverdon-les-Bains. (2014). Rapport final du Collège d'experts. Projet de réaménagement urbain et paysager de la Place d'Armes. Recuperado de http:// www.yverdon-les-bains.ch/fileadmin/templates/place-armes/_pdf/Rapport\%20 du\%20College\%20d\%27experts_27112014.pdf

Corajoud, M. (2012). Conférence Michel Corajoud, Journée Départementale du Paysage. Conseil Genéral Haute Savoi. Ambilly. Recuperado de https://www. youtube.com/watch?v=QZgaBsNEyEU

Davodeau, H., y Gomes Sant'anna, C. (2011). La participation du public et ses incidences sur l'évolution des théories et pratiques du projet des paysagistes. Territoire En Mouvement, (11), 50-65.

Donoso C. (Productor), y Araos S., y Cortese T. (Directores). (2005). Documental del Proyecto Quinta Monroy en Iquique, Chile [Documental]. Chile: Gobierno de Chile, Programa Chile Barrio. Recuperado de http://www.elementalchile.cl/en/projects/ quinta-monroy/ 
Fischer Pfaeffle, A. E. (2003). Devenires, cuerpos sin órganos, lógica difusa e intersexuales. En Diana Maffía (Comp.), Sexualidades migrantes. Género y transgénero (pp. 9-30) Buenos Aires, Argentina: Gráfica Integral

Jacobs, J. (2012) Déclin et survie des grandes villes américaines. Marseille, Francia: Éd. Parenthèses.

Joerin, F., Bombenger, P. H., y Cherqui, A. (2014). Démarche participative pour le projet de réamenagement de la place d'Armes. Analyse et synthèse de la démarche participative. Recuperado de http://www.yverdon.ch/deppar/_pdf/DEPPARRapportFinal.pdf

Joerin, F. (mayo, 2014). Réflexions sur une démarche participative au pays de la démocratie directe. Conférence-midi. École supérieure d'aménagement du territoire et de développement régional (ÉSAD) et du Centre de recherche en aménagement et développement (CRAD) de l'Université Laval. Recuperado de https://vimeo.com/111010603

Joerin, F. (octubre, 2017).¿ ¿nna herramienta participativa eficaz? [Encuesta en línea]. World Design Summit. Montreal, Canadá.

Godier, P. y Mazel, C. (s.f.). Projet des quais jardinets. Projets : Quais Rive Gauche. Bordeaux. Recuperado de http://www.popsu.archi.fr/sites/default/files/nodes/ document/685/files/projetquaisrivegauchegodiermazel.pdf

Lyotard, J. F. (1989). La condición posmoderna. Madrid, España: Cátedra

Lugones, M. (2011). Hacia un feminismo descolonial. La manzana de la Discordia, (6), 105-119.

MariedeBordeaux.(setiembredel2011).VilledeBordeaux.Dossierdepresse. Recuperado de http://www.bordeaux.fr/images/ebx/fr/groupePiecesJointes/27058/3/ pieceJointeSpec/114569/file/DP_bordeaux_2011_fr.pdf

Márquez, F. (2011). Planificación, diseño y gestión participativa del paisaje. Buenos Aires, Argentina: Editorial Nobuko.

Pardo Montañoso, A. M. (Octubre-Diciembre 2015). Migración internacional y desarrollo. Revista de Estudios Sociales. Recuperado de http://www.scielo.org.co/pdf/res/ n54/n54a04.pdf

Roche, D. (2010-2011). Aménagement des quais de la Garonne à Bordeaux. Les quais jardinés. Recuperado de http://dam.archi.free.fr/M1CV/Damien\%20ROCHE.pdf

Scribano, A., y De Sena, A. (2009). Construcción de Conocimiento en Latinoamérica: Algunas reflexiones desde la auto- etnografía como estrategia de investigación. Cinta De Moebio: Revista Electrónica De Epistemología De Ciencias Sociales. Recuperado de http://www.moebio.uchile.cl/34/scribano.html

Tapie, Guy. (diciembre, 2007). Quais rive-gauche, Tramway et autres espaces publics Bordelais. Recuperado de http://www.popsu.archi.fr/sites/default/files/nodes/ document/792/files/bordeaux-espace-public-g.tapie-quaisrivegauche-tramwayet-autres-espaces-publics.pdf

Venturi, R., Scott Brown D., e Izebour S. (2008). Aprendiendo de las Vegas. Barcelona, España: Gráficas 92, S.A. 